\title{
PARODIAS DE SITUACIONES Y VERSOS HOMÉRICOS EN ARISTÓFANES*
}

LUIS M. MACÍA APARICIO

Universidad Autónoma de Madrid

\begin{abstract}
Aristophanes often integrates in his comedies situations, complete lines, hemistichs or single words from the epic. The $\pi \alpha \dot{\theta} \theta \mathrm{o}_{\zeta}$ of such expressions powerfully contrasts with the linguistic and expressive context of his plays, and he thereafter obtains a strong comic effect. The use of verses different from the hexameter and, on the other hand, the authors' own interests acts against the litterality of the quotations. Moreover Aristophanes seems to consider Homer as the author of every epic word and, interesting enough, the presence of Homer in his comedies is more frequent than in other authors, like tragic or lyric poets, where this presence would be a priori more expectable. So Aristophanes frequently is the only witness of some Homeric expressions and topics in the litterature of the VIII-V b.C. centuries
\end{abstract}

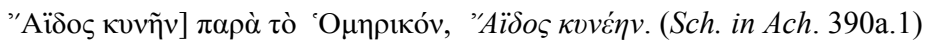

\section{Introducción}

La intención de este trabajo es continuar el análisis de la presencia de Homero en las comedias de Aristófanes, cuya primera parte, en la que se expusieron las bases generales, los objetivos y la metodología del mismo, hemos publicado recientemente ${ }^{1}$. Allí quedaron descritas las favorables condiciones que permiten

* Este trabajo ha sido realizado con financiación de la DGICYT, dentro del Proyecto de Investigación «La épica homérica y su tradición textual y literaria» (PB95-0191). Ha contado con las observaciones y críticas de amigos y compañeros, que agradezco profundamente. En las referencias a autores y obras seguimos las pautas del Diccionario Griego Español, Madrid, CSIC, $1980-$

1 L.M. Macía Aparicio, «Homero y Aristófanes», en pp. 199-209 de L.Gil Fernández et

EMERITA. Revista de Lingüística y Filología Clásica $(E M)$ — LXVIII 2, 2000

pp. 211-241 
a los autores de la comedia, siempre atentos a lo cotidiano, integrar en sus piezas por la vía de la parodia y de la crítica literaria fragmentos más o menos extensos de la producción ajena; se expusieron también las líneas generales de lo que pretende ser un estudio completo de la presencia de Homero y la épica en Aristófanes, que se inició con el análisis de las citas homéricas directas; a él remito también para cuestiones bibliográficas, relacionadas con la tradición indirecta en general y con la importancia de Aristófanes dentro de ella. Parece oportuno, no obstante, insistir brevemente en lo allí expuesto, con vistas a facilitar la lectura de este trabajo. Las comedias de Aristófanes - la Comedia en general - ofrecen de un modo voluntario o involuntario numerosos ejemplos de producción ajena integrada en su trama general o en escenas puntuales al servicio de sus propios intereses. Después de la tragedia, el género épico en general y Homero en particular es uno de los que con más frecuencia podemos detectar $^{2}$. La nobleza y solemnidad de su ethos se opone a la vulgaridad del contexto en que suele incluirse y ese contraste resulta cómico.Para establecer el conjunto de pasajes aristofánicos que habría que analizar hemos rastreado en Aristófanes la presencia de homerismos y epicismos, que hemos comprobado $\mathrm{y}$, en su caso, ampliado por medio de la consulta de traducciones y comentarios de las comedias de Aristófanes, que suelen indicar los paralelos entre el cómico $\mathrm{y}$ otros autores, y de los escolios antiguos, fuente habitual, aunque no siempre reconocida, de muchos de esos paralelos citados por los modernos. Ese corpus, incompleto si se nos ha pasado por alto algún ejemplo, o más extenso de lo debido, si alguno no le pertenece en rigor - de hecho, es probable que alguno de los ejemplos que citamos reflejen la presencia en Aristófanes de un topos que documentan igualmente Homero, la épica u otros autores -, fue clasificado

al. (edd.), Corolla Complutensis. Homenaje al Prof. J. Sánchez Lasso de la Vega, Madrid, 1998, un trabajo que, como el que aquí ofrecemos, comparte mucho en intención y método con los de otros miembros del equipo investigador del PI citado más arriba, cf., por ejemplo, los dedicados a la tradición indirecta de Homero en Aristóteles por M. Sanz Morales (especialmente su El Homero de Aristóteles, Amsterdam, 1994) y J. B. Torres Guerra, «El Homero de Jenófanes», Emerita 67, 1999, pp. 75-86. Asimismo, presenta ciertas semejanzas, debidas al parecido entre

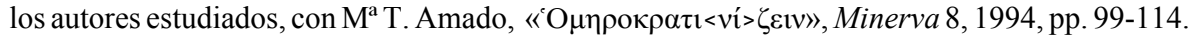

2 Resulta extraña en esas condiciones la escasa atención que recibe Aristófanes en los manuales de crítica textual y estudios de tradición indirecta y el exiguo espacio que se le concede a la presencia de lo épico en su obra. López Eire, por ejemplo, en su excelente estudio de la lengua de la comedia (Emerita 54, 1986, pp. 237-74), apenas alude (p. 241) a la deformación cómica de un epíteto y de una expresión homérica muy frecuente en Eq. 297-300. 
provisionalmente en cinco apartados ${ }^{3}$, el primero de los cuales fue estudiado, como ya se ha dicho, en nuestro trabajo anterior. Atendemos ahora a los grupos segundo y tercero y dejamos para otra ocasión el análisis de los dos restantes por no alargar este trabajo en exceso.Con escasas variaciones, una vez definido el pasaje aristofánico que recuerda la épica por un motivo o por otro, todos los casos son analizados de la siguiente forma: 1) búsqueda en los poemas homé$\operatorname{ricos}^{4}$ del precedente del pasaje aristofánico, con el propósito de determinar su posible carácter de parodia homérica; 2) rastreo del pasaje en el resto del género épico, incluyendo a poetas antiguos y posteriores a Aristófanes ${ }^{5}$. La justificación de esta operación, que, evidentemente, cuando se aportan paralelos de autores posteriores a Aristófanes, no pretende demostrar una imitación avant la lettre, es doble. Por una parte, Aristófanes considera obra de Homero prácticamente todos los poemas épicos; por otra, la presencia de epicismos en la comedia, aunque no se encuentren en la Ilíada ni en la Odisea, refleja, a mi juicio, el mismo tipo de utilización paródica que se hace de los poemas de Homero; 3) búsqueda de paralelos o precedentes en los autores de la literatura griega entre los siglos VIII y V a.C., con el propósito de determinar hasta qué punto Aristófanes es testigo único de los pasajes homéricos que introduce en sus obras o está inserto en una tradición bien representada.Para realizar esas búsquedas hemos manejado una base de datos informatizada, cuyo material hemos completado en aquellos autores no incluidos en ella con las ediciones más modernas de los mismos ${ }^{6}$.

3 Respectivamente, 1) citas directas; 2) situaciones, escenas o episodios completos; 3) versos de apariencia homérica; 4) epítetos y fórmulas de colorido épico y 5) ecos, loci similes, etc. Somos conscientes, sin embargo, de que ninguna clasificación es capaz de resolver el problema de los ejemplos mixtos y de que más de uno de ellos podría entrar en grupos distintos de aquel en que lo incluiremos.

4 En realidad, probablemente la imagen de un poeta, Homero, autor de unas obras concretas, Ilíada y Odisea, responde más al concepto moderno de autor y obra que a la realidad de los hechos. No obstante, en este trabajo daremos por buena la atribución a Homero de esos dos poemas y exclusivamente de ellos. En cuanto a la polémica acerca de la fecha de Homero y sus poemas, creemos que carece de relevancia para los objetivos que se persiguen en este trabajo.

5 Aunque en rigor no pueda decirse que pertenecen a ese género literario (de hecho la base de datos que manejamos no los incluye en él), hemos admitido entre los ejemplos de la épica los pertenecientes a la colección de Himnos Homéricos, debido a su afinidad de contenido con aquélla y a que el hexámetro dactílico es su forma de expresión.

6 Thesaurus Linguae Graecae (TLG 5.0). Univ. de California, 1992. Para los épicos arcai- 


\section{Parodias de situación con indicación de autor}

Las comedias de Aristófanes incluyen como propias algunas escenas y ciertos términos que forman parte del argumento de los poemas homéricos o son en ellos motivos y temas recurrentes. Presentamos los ejemplos por el orden cronológico generalmente aceptado para las once comedias.

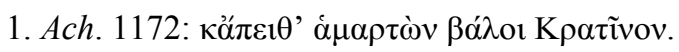

Los escolios sólo comentan que el Cratino de este verso no es el viejo poeta cómico, rival de Aristófanes, sino cierto individuo de ese nombre, fanfarrón, pendenciero y borracho ${ }^{7}$. Sea como sea, tenemos en este verso un ejemplo del motivo homérico del tiro fallido ${ }^{8}$, que se presenta en aquellos poemas de un modo más o menos completo y desarrollado, según los casos.

El motivo tiene un desarrollo completo, como en el verso aristofánico, cuando a la mención del fallo en el objetivo deseado le sigue la indicación del blanco realmente

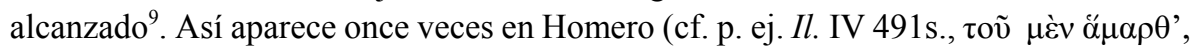
ö $\delta \grave{\varepsilon} \Lambda \varepsilon \tilde{v} \kappa o v ~ . . . \beta \varepsilon \beta \lambda \eta ́ \kappa \varepsilon 1)$.

Presenta, en cambio, un desarrollo incompleto cuando se menciona solamente el fallo. Así aparece en Il. V 287; X 372, un tiro fallado a propósito, XI 223 (= XIII 605), XVI 336, 477 y XXII 279.

Fuera de Homero, la épica no presenta ejemplos de ese motivo, y en la literatura de los siglos VIII-V sólo Heródoto utiliza el motivo del tiro fallido en la narración de un hecho histórico, aunque los términos empleados y su distribución son distintos de los

cos, no todos ellos incluidos en la versión actual del $T L G$, hemos manejado la edición de A. Bernabé, Poetae Epici Graeci. Pars I, Testimonia et Fragmenta, Leipzig, 1987. A los testimonios de la expresión Movбó $\omega v \theta \varepsilon \rho \alpha ́ \pi o v \tau \varepsilon \varsigma$, que citábamos en nuestro trabajo ya mencionado como paralelos para $A v .908$, podemos añadir ahora, gracias a su consulta, el fr. 2.2 de Quérilo de Samos.

No se ve, sin embargo, la razón que justifique ese aserto ni qué problemas conlleva pensar lo contrario. De hecho, tanto V. Coulon-H. Van Daehle (Aristophane I-V, París, 1967-72 - Coulon a partir de ahora), como E. Rodríguez Monescillo (Aristófanes. Comedias I, Madrid, 1985 - en adelante Monescillo), como L. Gil Fernández, (Aristófanes. Comedias I, Madrid, 1995 - Gil) coinciden en esa identificación.

8 Así lo indica Gil, ob. cit., que comenta el carácter homérico del pasaje, así como el del proyectil aquí mencionado, $\mu \alpha ́ \rho \mu \alpha \rho o v$ (cf. Il. XII 380; XVI 735 y Od. IX 499; cf. también E., Ph. 663; 1401 y Helanico 1 a, 4 F 96), pero no Coulon ni Monescillo.

"Apunta a un farol y mata a una vieja”, decimos en castellano. Sobre el valor de los verbos empleados en la expresión homérica de este motivo, véase L. Conti, «Zur Bedeutung von

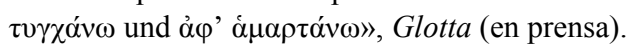




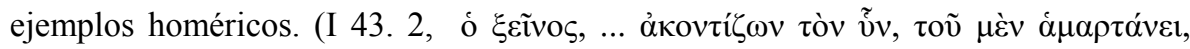

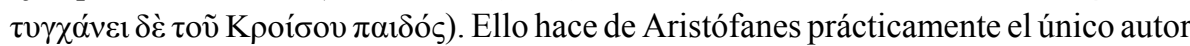
que se hace eco de semejante homerismo ${ }^{10}$.

La expresión del cómico es completamente similar a los ejemplos homéricos señalados ${ }^{11}$, aunque mucho más condensada, poniendo en vecindad absoluta el fallo y el acierto, que en la mayoría de aquéllos se mencionan separados con el intervalo de un verso o más. En ese sentido se parece más al ejemplo de Heródoto recién citado, pero pensamos que es Homero el autor que Aristófanes quiere sugerir a su público. En cuanto al pasaje concreto que se parodia en esta ocasión, creo que es imposible de identificar, ya que sólo se pretende evocar un motivo homérico muy frecuente ${ }^{12}$.

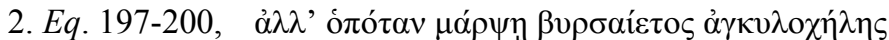

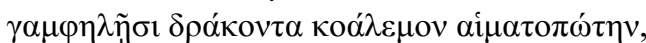

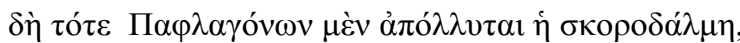

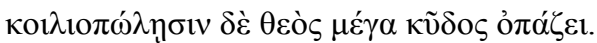

Casi todos los comentaristas señalan la evidente parodia del estilo oracular de este pasaje $^{13}$. La relación entre los oráculos y la épica es, por otra parte, algo bien conocido ${ }^{14}$ y se han señalado diversos ejemplos de ese género como precedentes o imitados en éste. Los escolios antiguos advierten de la frecuencia en los oráculos de un comienzo como $\dot{\alpha} \lambda \lambda$ ' ómótav. A su vez, Coulon y Gil señalan con toda razón su semejanza con Il. XII 200-207, que describe un presagio en el que aparece un águila que lleva entre sus garras ensangrentadas una serpiente, pasaje que ofrece ciertamente un parecido general bastante notable y una fácil identificación de la serpiente con las morcillas que fabrica Agorácrito, pero cuyas similitudes no bastan, a mi juicio, para reconocerle la

10 Ese carácter de conservador único o casi único de homerismos parece corriente entre los poetas de la Comedia Antigua, a juzgar por la situación de Cratino, cf. M ${ }^{\mathrm{a}} \mathrm{T}$. Amado, en págs. 105,113 de «O

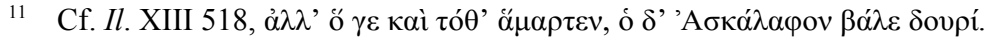

12 No creemos demostrada la identificación que propone E. K. Borthwick (apud Gil, ob. cit.) con Il. V 580 ss., basada en que Aristófanes mencione un arma "no convencional", pues, de hecho, los tiros de piedra dan en Homero siempre en el blanco (a excepción de $\mathrm{Il}$. XX 286, donde el fallo se debe a la intervención directa de un dios).

13 Aparte de Coulon y Gil, ya citados, véase R.A. Neil, The knights of Aristophanes, Hildesheim, 1966; no menciona el homerismo M. Landsfester, Die Ritter des Aristophanes, Amsterdam, 1967. Dedicamos aquí nuestra atención al conjunto del pasaje, reservando para otro lugar de este trabajo más acorde con nuestra clasificación el análisis de algunas expresiones concretas, como la del v. 200, contenidas en él.

14 Destacan los numerosos trabajos que al tema le ha dedicado J. A. Fdez. Delgado. Véase, entre ellos, Los oráculos y Hesíodo: Poesía oral mántica y gnómica griegas, Cáceres, 1986. 
consideración de modelo concreto imitado en estos versos aristofánicos. También podría citarse como pasaje homérico más cercano $O d$. XIX 538, si bien, a diferencia de los otros posibles modelos mencionados más arriba, la semejanza con éste es menos

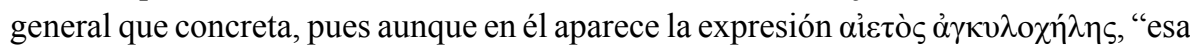
águila se deja caer sobre unas ocas".

En consecuencia, nos encontramos ante la imitación general de una escena homérica contenida en un pasaje oracular, posiblemente $I l$. XII 200-207. Y en este sentido queremos destacar que ni en la épica ni en la literatura de los siglos VIII-V hemos encontrado ningún ejemplo semejante.

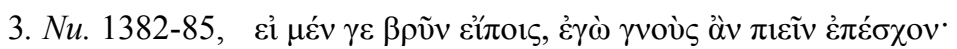

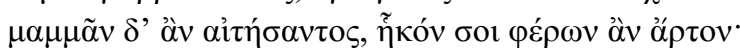

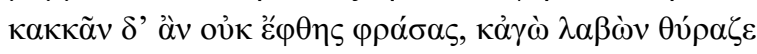

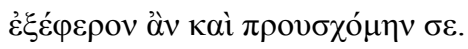

A pesar de que los escolios y la mayoría de los comentaristas modernos guarden silencio sobre la posibilidad de que en este pasaje tengamos una parodia de Homero, parece evidente la semejanza de la situación general, aunque no de cada uno de los cuidados que Estrepsiades dice haber dispensado a Fidípides en su niñez, con la que describe Fénix, el viejo ayo de Aquiles, en la escena de la embajada, Il. IX 486-92 ${ }^{15}$.

Tanto Fénix como Estrepsiades actuaron con igual cariño y abnegación, pero aunque en términos generales la situación es similar, el dramatismo de la escena iliádica que probablemente se parodia aquí, sumado a la nobleza de los caracteres heroicos en ella implicados, a la fuerza tenía que contrastar vivísimamente con la garrulería y vulgaridad de las palabras del viejo ateniense, protagonista de las Nubes, quien, no obstante, comparte con su noble predecesor la expresión de su amargura por el pago que sus respectivos pupilos les dan por sus cuidados de antaño.

Aparte del posible paralelo esquíleo que señala Coulon, Aristófanes es, una vez más, el único autor que ofrece una muestra de ese tema en el marco cronológico y literario considerados en este trabajo.

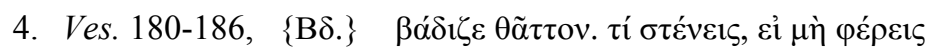

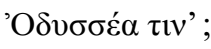

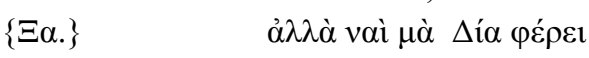

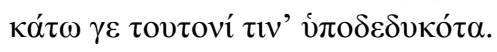

15 No se le escapa el parecido a Van Leeuwen, Aristophanis. Nubes, Leiden, 1968 (= 1898), pero sí a Coulon y a Starkie, Aristophanes. Clouds, Amsterdam, 1966 (=1911). Coulon menciona unos versos parecidos en boca de la nodriza de Orestes en las Coéforos de Esquilo, vv. 751-62. 


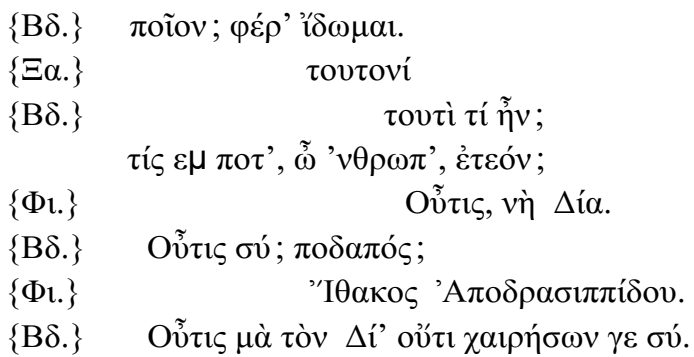

En nuestro trabajo anterior hemos descrito los rasgos más generales de este ejemplo, de cuyo carácter de parodia de la famosa escena de la fuga de Odiseo y sus compañeros de la cueva de Polifemo, que se relata en el canto noveno de la Odisea, dan noticia los escolios y no deja de señalarse en los comentarios modernos. Para la identificación del

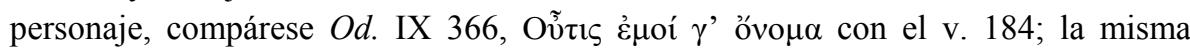
extrañeza que muestra Tiracleón por la tardanza del asno es la que expresa el Cíclope (ibid.447-52) ante el retraso de su carnero favorito. Hemos señalado también ya que el juego de palabras aquí directamente parodiado tiene una segunda edición en los vv. 907 ss. de Las Tesmoforias ${ }^{16}$.

El episodio homérico fue tratado también por Eurípides en su drama satírico $E l$ Cíclope, pero en la literatura de los siglos VIII-V no encontramos ya más ejemplos, ni siquiera en Los Odiseos de Cratino, aunque en este caso la ausencia de esta escena obedece, sin duda, al estado fragmentario de su conservación ${ }^{17}$.

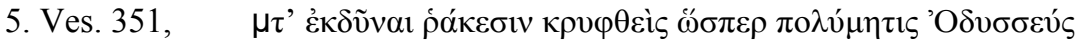

Aunque no lo señala Coulon en su comentario, parece muy probable a simple vista que en este verso tengamos una nueva parodia de situación, referida a alguna de las numerosas artimañas de Odiseo: para salir de su encierro, Filocleón podría buscar un canalón (v. 350) y deslizarse por él disfrazado con harapos de mendigo como el muy astuto Odiseo. Semejante procedimiento encajaría bien con las mañas del héroe, pero en los poemas homéricos no hay ningún pasaje concreto que pueda aducirse como

16 Aristófanes juega allí, parodiando la escena de una tragedia de Eurípides, con el doble valor de adjetivo y nombre propio de la palabra helena.

17 Ya hemos señalado la voluntad de Aristófanes de traer a sus comedias palabras de otros autores e integrarlas en ellas para provocar risa. El hecho parece ser característico de la Comedia en general, sobre todo cuando era difícil ejercer la crítica política directa, pues, como ha puesto de relieve $\mathrm{M}^{\mathrm{a}}$.T. Amado, Cratino muestra semejante intención. No obstante, el viejo cómico ofrece más ejemplos de parodias de situación que de versos concretos (lo que es lógico, pues es el tema de su comedia el que parodia un episodio homérico) que Aristófanes, en cuyas obras es más frecuente la parodia de palabras que la de escenas. 
referencia exacta. Vayamos por partes.

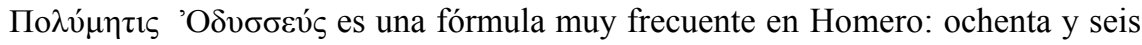
ejemplos, sesenta y ocho de ellos en la Odisea, y una sola ocasión en que el adjetivo no se le aplica a Ulises ${ }^{18}$. Fuera de Homero el conjunto no tiene más ejemplo que este verso y también es escasa la representación del adjetivo ${ }^{19}$. Éste es, a mi entender, un detalle de gran importancia para interpretar el verso en conjunto y referirlo en general a la Odisea y su ambiente.

Por otra parte, el uso de harapos como disfraz es un motivo odiseico muy conocido: es así como Ulises puede regresar a su patria y engañar a los pretendientes para darles muerte. Sin embargo los escolios al verso 350, comentando ỏ $\pi \eta$, el agujero o canalón, afirman que estos versos se refieren a la ocasión en que aquél (y Diomedes) penetraron en Troya por una alcantarilla para robar el Paladio. Y ahí comienzan las dificultades:

En Od. IV 245 Helena relata la entrada en Troya de Ulises como espía en busca de

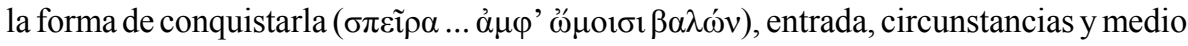

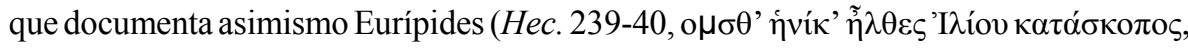

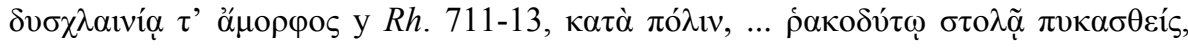
ejemplo bastante cercano al nuestro por la presencia del adjetivo $\rho \alpha \kappa o \delta v ́ \tau \omega)$.

En cuanto al tema del robo del Paladio que protegía a Troya y la hacía inexpugnable, no está en Homero, pero sí en el Ciclo: aparece en la Iliupersis (fr. 1. 28-29 Bernabé) y en la Pequeña Ilíada (fr. 1. 17-18 Bernabé). También en el Reso de Eurípides (vv.

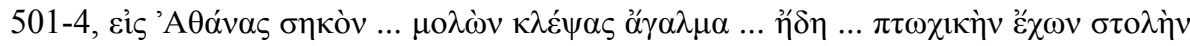
$\dot{\varepsilon} \sigma \tilde{\eta} \lambda \theta \varepsilon \pi u ́ \rho \gamma o v \varsigma)$. Los ejemplos mencionados documentan, pues, la presencia de Odiseo en Troya en dos ocasiones diferentes: una primera, en la que entró en la ciudad para espiar, y una posterior, en la que robó el Paladio, si bien el pasaje del Reso (vv. 711-13) las presenta en orden inverso ${ }^{20}$. La Pequeña Ilíada, en efecto, las presenta en

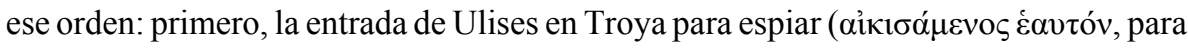
lo cual se hizo desfigurar el rostro a golpes por Toante (fr. 7, 4-5 Bernabé, una forma de pasar inadvertido distinta a los harapos y las alcantarillas de las otras fuentes), y después el robo del Paladio, acompañado de Diomedes.

En cuanto al medio empleado para penetrar en la ciudadela troyana, las fuentes se refieren principalmente a la ocasión en que entró para espiar y, salvo en la versión de la Pequeña Ilíada, coinciden en los harapos como disfraz, aunque sólo $R h .710$ emplea la palabra ṕókos. El único testimonio que, aun sin especificar que fue para robar el Paladio, alude al camino secreto, a la alcantarilla, como el escolio al v. 350 antes

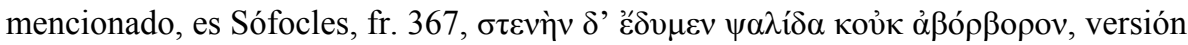

18 Il. XXI 355, aplicado a Hefesto, como en Helanico, fr. 1 a 4.

19 h. Merc. 319; h. Hom. 28, 2; Forónide, fr. 2. 5 Bernabé; Matrodoro, test. 6. 7 Bernabé.

20 Un cómodo resumen en Apolodoro, Epit. 5.13. 
que ofrece igualmente Servio, Aen. II 166.

El conjunto de testimonios aducidos permite, pues, distinguir dos entradas de Ulises en Troya, para espiar y para hacerse con el Paladio, y dos medios distintos de hacerlo, disfrazado y por una conducción de agua, si bien no es posible establecer con precisión la relación exacta entre entradas y medios de hacerlo. Nuestro escolio al v. 350 parece interpretar que Aristófanes lo ha mezclado todo, al identificar una de las entradas con los dos medios empleados, pues carece de sentido disfrazarse si se va a utilizar un camino secreto o usar éste si ya se va disfrazado. Esa posible contaminación parece a primera vista la explicación más plausible y es la que aceptan en su mayoría los comen$\operatorname{taristas}^{21}$, pero caben otras posibilidades.

Ante todo, conviene recordar que el Ulises que Aristófanes pone como modelo para Tiracleón sale de un lugar, en tanto que el de sus posibles modelos entra; en segundo lugar, que salvo el paralelo más cercano a este verso, el de $R h .710$, ninguno de los posibles precedentes comparte con él cuestiones tan fundamentales como la adjetivación del héroe o, sobre todo, la mención explícita de los harapos, que constituyen la base del disfraz en nuestro verso y que ambos detalles son iguales en la Odisea ${ }^{22}$; en tercer y

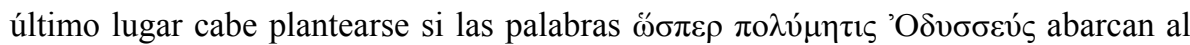
truco del canalón o, como el orden de palabras parece sugerir, sólo al disfraz con harapos, pues en este caso Aristófanes no sería culpable de contaminación, sino que se referiría a una sola situación.

Por mi parte, aun con dudas, creo que esta explicación es preferible, pues a mi entender lo más característico de este Ulises aristofánico y, por lo tanto, lo que se parodia aquí, es su gran capacidad para urdir tretas y la del disfraz es una de las más conocidas.

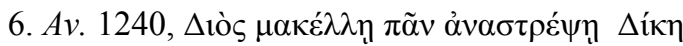

El azadón bifurco es un apero de labranza. En Il. XXI 257 ss. es la herramienta que se usa para desatascar una acequia de las piedras y el ramaje que la obstruyen. Y si el azadón es de Zeus, nos hallamos ante una metáfora de su arma favorita, el rayo, con el que despeja su camino y elimina cualquier obstáculo, humano o divino, que se opone a los designios de su voluntad. Así es como se le nombra en Sófocles, fr. 727, cuyo carácter modélico respecto a nuestro verso señalan los escolios ${ }^{23}$.

21 W. J. M. Starkie, Aristophanes. The Wasps, Amsterdam, 1968 (= 1897); D. M. Mac Dowell, Aristophanes. Wasps, Oxford, 1971.

22 Por esa razón Van Leeuwen, Aristophanes. Vespae, Leiden, $1909(=1968)$ prefiere la Odisea como marco de referencia global para esta parodia.

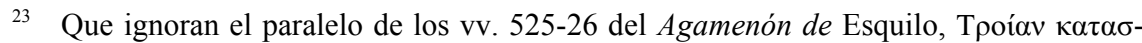

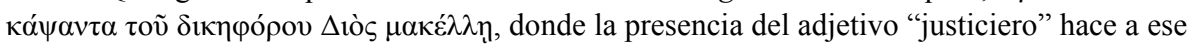


Quizá tengan razón los escolios y sea Sófocles el imitado. En ese caso nos hallaríamos ante una parodia del grandilocuente estilo de los trágicos, que, sobre todo en el caso de Eurípides, tanto fustiga nuestro poeta; pero creo que bajo el empleo de esa metáfora trágica subyace una nueva parodia de situación de la épica homérica, la del gran Zeus atacando y destruyendo con el rayo a sus enemigos, tal como lo vemos, entre otros ejemplos, en $O d$. V 128. Verdad es que en todos los ejemplos homéricos el rayo es nombrado directamente, nunca mediante la metáfora del azadón, con lo cual, si estamos en lo cierto, lo que hace Aristófanes es convertir en ridícula la acción de Zeus, al presentarle manejando una humilde herramienta de labrador para dar rienda suelta a su terrible cólera: lo que en los trágicos es una agudeza léxica, un artificio literario, sería ahora una burla, una imagen grotesca del dios completamente indigna de su majestad.

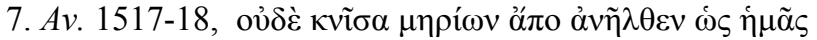

La fundación de Piopío de las Nubes impide hace tiempo que los dioses reciban en su morada el humo de la grasa de los sacrificios. Las escenas épicas de sacrificio vienen inmediatamente a nuestra memoria ante esta frase, aunque no puede citarse ningún punto en Homero donde una frase así se repita. Podrían mencionarse, no obstante, numerosos paralelos, entre los que el más apropiado ${ }^{24}$ es probablemente $I l$. I 317 . El motivo es claramente épico y se encuentra también en el Himno a Apolo (vv. 58-59).

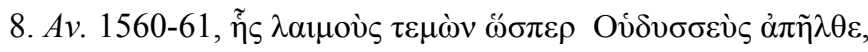

Coulon propone $O d$. XI 49 y 82 como referencia, pero creo que es preferible ibid.

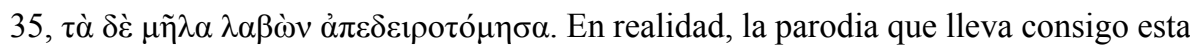
escena afecta en su conjunto a la parte de la Nekuia odiseica en que se narran los sacrificios propiciatorios ofrecidos a las almas de los muertos, si bien aquí, con vistas a la comicidad de la referencia, la oveja y el cuello de allí se convierten en la 'camellacordera' y el 'gañote' de este verso. Los escolios no indican el aparente paralelo homérico ${ }^{25}$ y afirman que la parodia se emplea para hacer una crítica de los filósofos: seres sin alma y que frecuentan las sombras.

verso bastante parecido al nuestro, en el que es la mismísima Justicia la que manejará el azadón bifurco para aniquilar a los impíos.

24 Véanse, además, Il. IV 49 (= XXIV 70) y VIII 549.

25 Si lo hay, es, en efecto, más general que concreto. Homero emplea $\lambda \alpha u \mu$ ó cinco veces, aunque ninguna de ellas en contexto de sacrificio. La palabra es frecuente en Eurípides, que en Helena 1584 ofrece un paralelo bastante cercano a nuestro verso, pero que no puede ser modelo de éste, pues esa tragedia es posterior a esta comedia. 


\section{Plu. $290-315$}

Los escolios indican que este pasaje está tomado del Cíclope de Filóxeno ${ }^{26}$, uno de los autores contemporáneos de Aristófanes más ridiculizados por el cómico, del que se burla por haber convertido al salvaje Polifemo homérico en un citarista enamorado y vegetariano. Pero a lo largo de este amplio pasaje los escolios señalan también paralelos con la Odisea, como no podía ser menos, dado que ese poema es en último término el modelo de las imitaciones de Filóxeno y Aristófanes. En efecto, al comentar el v. $312^{27}$, los escolios se hacen eco de la imitación de varios pasajes odiseicos; el escolio, a cuyas palabras añadimos nosotros la identificación de los pasajes, afirma que habría sido más correcto que Aristófanes dijera "te pondremos una espada en el pecho", como hizo Ulises con Circe (Od. X 321-22, siguiendo el consejo de Hermes, ibid. 294-95), pero que el cambio de esas palabras pretende que lo sucedido con Circe sea igual que lo que le pasó a Odiseo cuando se colgó del cabrahígo durante el episodio de Caribdis (ibid. XII 432) o cuando por orden de aquél Eumeo y Telémaco colgaron al cabrero Melanto (ibid. XXII 187-94). Es decir, que Aristófanes habría imitado, deformándolos además, pasajes bien conocidos, lo que sin duda provocaría una reacción de sorpresa en su auditorio, que ya se habría quedado perplejo por la identificación de Laide con Circe y porque ésta y Filónides, identificado a su vez con Odiseo, sean los protagonistas del mito ${ }^{28}$.

En otro orden de cosas, cabe señalar el paralelismo de los versos en que se menciona a Laide, como Circe, mezclando mierda para atraer a los compañeros de Filónides, remedo de Ulises, y Od. X 233 ss. Resulta, sin embargo, notable que la propia actividad

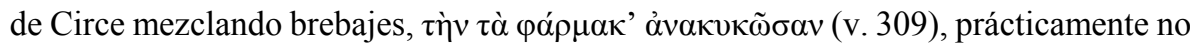
sea mencionada en Homero. En sus poemas se citan con frecuencia los $\varphi \alpha ́ \rho \mu \alpha \kappa \alpha$, habitualmente en conexión con alguna forma del verbo $\pi \alpha ́ \sigma \sigma \omega$, pero nada se nos dice acerca de cómo se fabrican, pues en el episodio de Circe ya mentado (Od. X 235-36,

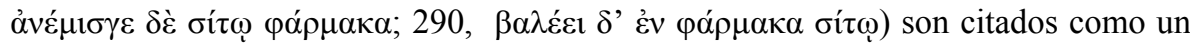
producto ya hecho; sólo en $O d$. IV 230, $\varphi \alpha ́ \rho \mu \alpha \kappa \alpha ~ . . . \mu \varepsilon \mu \imath \gamma \mu \varepsilon ́ v \alpha$ se alude a la mezcla como génesis de aquéllos, aunque el verbo empleado es diferente del que usa Aristófanes en este pasaje, otra nueva deformación si el modelo homérico estaba en su

26 Según los escolios, el v. 292 de Pluto está tomado directamente de esa obra.

27 Los vv. 309-12 de Pluto, que canta el coro en respuesta a unos muy similares que acaba de decir Carión (vv. 302-5), rezan así: "Desde luego que a ti, aquella Circe que brebajes mezclaba, preparaba filtros y manchaba a los compañeros, te vamos a echar mano por puro placer, e imitando al hijo de Laertes te vamos a colgar por los cojones" (Con la cursiva indicamos la transformación que señalan los escolios).

28 Las identificaciones son sencillas: como Circe, Laide atraía a sus amantes con brebajes; en cuanto a Filónides, llamaba "jabalíes" a sus colegas, y en cerdos se convirtieron los compañeros de Ulises por culpa de Circe. 
cabeza.

\section{Versos y miembros de versos homéricos sin indicación explícita de autor}

Desperdigados por las comedias, con fidelidad al modelo o deformados - a veces por la necesidad de ajustarse a un esquema métrico ajeno al dactílico, a veces simplemente para obtener una mayor comicidad -, encontramos versos o segmentos de versos homéricos o épicos que sorprenden al auditorio con su solemnidad inesperada, insertos en un contexto de tono más bien vulgar por lo general $^{29}$.

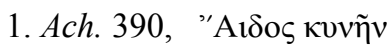

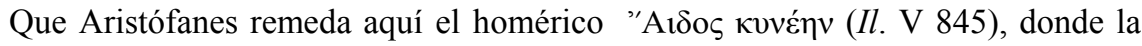
forma antigua no contracta está exigida por la métrica ${ }^{30}$ lo señalan los escolios y es sorprendente que no lo hagan ni Coulon, ni Monescillo ni Gil. La mención del casco mágico de Hades, que hacía invisibles a sus portadores, para describir la enmarañada cabellera de Hierónimo es un buen ejemplo de homerismo conservado casi exclusivamente por nuestro cómico. De hecho, en el género épico sólo se le cita en el Escudo pseudohesiódico (v. 227) y en dos pasajes de las Dionisiaca de Nonno (XXII 55 y XLVII 524) y en la literatura de los siglos VIII-V sólo lo hace Platón (R. 612 b).

Esa situación resulta relativamente extraña, sobre todo por lo que se refiere a la tragedia, cuya mayor proximidad a la épica respecto a la comedia es generalmente admitida $^{31}$. Aquélla, en efecto, toma de la épica el tono general y prácticamente la totalidad de sus temas; en ella son muy abundantes los epítetos épicos y las escenas y situaciones que recuerdan pasajes de ese género o que están tomados directamente de él, cosa que, como hemos visto, es menos frecuente en la comedia, al menos en Aristófanes. Pero el caso es otro si nos fijamos en el empleo de versos y expresiones épicas

29 No haremos aquí el análisis de Ves. 1520-21, para el cual remitimos a nuestro «Homero y Aristófanes», ob. cit. pp. 202-3.

30 Del mismo modo que en nuestro verso lo está la contracta, pues кvvĩv ocupa el último pie del verso, un trímetro yámbico, y en esa posición no es posible el anapesto. De todas formas, todas las apariciones de esa palabra en Aristófanes presentan la forma contracta, independientemente de su lugar en el verso.

31 Cameleonte de Rodas (apud Ath. VI 277 e) decía que Sófocles se abastecía de la cantera homérica y es notorio que los ciclos tebano y troyano están en la base de sus obras; véase también una lista de motivos (no exhaustiva, según el autor) que comparten los tres trágicos entre sí y, frecuentemente, con la épica, que aporta J. Vara (en J. A. López Férez (ed.) Historia de la Literatura Griega, Madrid, 1988, pp. 319-21. 
en los dos principales géneros dramáticos. Al analizar las citas homéricas directas vimos ya indicios de una tendencia que ahora se confirma en un número bastante elevado de los ejemplos que estudiamos en este trabajo: Aristófanes integra algunas veces en sus piezas expresiones de esa clase que no se documentan en la tragedia; con ello no queremos decir que él sea conservador único de lo épico en la poesía dramática, pues en alguna ocasión ejemplos épicos presentes en los trágicos están ausentes de su obra ${ }^{32}$, pero sí que lo es en numerosos ejemplos que él cita y que carecen de correlato en aquéllos.

¿Obedece este hecho al azar de la tradición manuscrita, que nos ha permitido conservar sólo una mínima parte de la obra de los trágicos? ¿Es fruto de la dificultad de introducir palabras de ritmo dactílico en la métrica de la tragedia? ¿Refleja el interés de los trágicos de marcar diferencias con la épica con la que comparten tema y ambientación? El tema merecería un estudio particular que excede de los límites de este trabajo ${ }^{33}$.

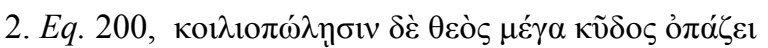

El oráculo imitado en el pasaje analizado como ejemplo 2 del grupo anterior termina con este hexámetro, impecable desde el punto de vista métrico e incluso como predicción, pero ridículo por la afirmación de que los morcilleros recibirán de los dioses

32 Véanse, por ejemplo, los ecos casi literales de Il. I 5 en Esquilo, Supp. 800-801, Eurípides, Hec. 1077 e Ion 505 y los más lejanos de Sófocles, Ant. 205-206 y Heródoto, VII 10, q 3, un ejemplo en el que, no obstante, es posible que estemos más bien ante la presencia de un lugar común en varios autores que ante la imitación consciente de uno de ellos por los demás.

33 Sin embargo, siquiera sea de modo provisional, merece la pena responder brevemente a esas interrogantes. La primera de ellas es rechazable por inverificable y porque igualmente sería posible que en las comedias aristofánicas no conservadas estuvieran esos ejemplos que transmiten los trágicos o bien nuevos ejemplos épicos ausentes en éstos; el argumento basado en la métrica es igualmente desechable, pues aunque el ritmo de la comedia tampoco es fundamentalmente el dactílico, Aristófanes no parece tener problemas para integrar, deformados o literales, versos y cola de ese ritmo. Sólo la tercera explicación parece, en principio, plausible: los trágicos necesitarían un lenguaje especial, distinto del de la épica por un doble motivo. Primero, por hacer diferente en algo sus obras de la épica, con la que comparten tema y ambiente; segundo, porque las expresiones de la épica, reflejo de su concepción del hombre y el mundo, resultarían, por fuerza, pasadas de moda y, grave peligro, potencialmente ridículas, porque en la época de la tragedia esa concepción había experimentado profundos cambios. Tanto los héroes de la épica como los de la tragedia son, cada cual en su momento, personajes serios, y si los de esta última hablaran en el siglo $\mathrm{V}$ con el mismo lenguaje que aquéllos, resultarían anacrónicos y producirían un efecto devastador sobre la seriedad de la obra. En esas condiciones, la opción de la tragedia es emplear un lenguaje elevado, pero adecuado a las circunstancias de su tiempo. 


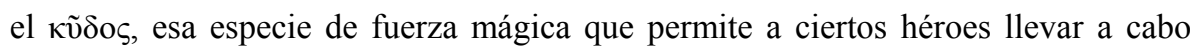
acciones sobrehumanas en algún momento. La mezcla de lo épico y lo grotesco en aras, una vez más, de la comicidad. Centrémonos en la parte épica de este verso, desde la cesura heptemímeres $^{34}$ al final.

Es preciso señalar ante todo que la idea que expresan esas tres palabras es muy frecuente en la épica, pero que su aparición conjunta es absolutamente exclusiva de este ejemplo.

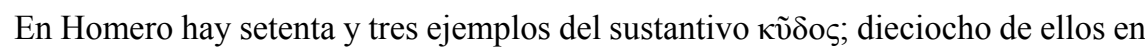

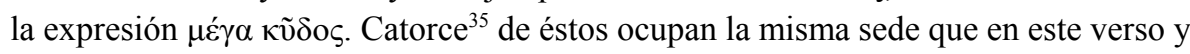
cuatro (p. ej. Il. VIII 176), otra distinta; en cuanto a su combinación con formas del verbo ỏ $\pi \dot{\zeta} \zeta \omega$, son diez los ejemplos, nueve de los cuales (p.ej. Il. VII 205) forman, como aquí, el adonio final y uno (Il. XIV 358), ocupa sede diferente. Por su parte, ỏ $\pi \dot{\zeta} \zeta \omega$, aparte de los ejemplos en que se combina con $\kappa \tilde{\delta} \delta$ o, , se muestra en Homero nueve veces, ocho de las cuales aparece en final de verso (p.ej. Il. IV 321) y una (Il. XI 493) en otra sede ${ }^{36}$. Como dijimos, se trata de una expresión bien asentada en Homero, pero que no aparece nunca en la forma que ha usado Aristófanes.

El resto de la épica ofrece un panorama semejante. Autores como Paniasis (fr. 17.9 Bernabé) y Quérilo (fr. 20.9; 22.35 Bernabé) presentan sólo ejemplos del verbo, con

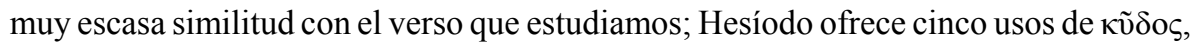
todos ellos similares por la sede métrica que ocupan ${ }^{37}$ y entre los que merece mención

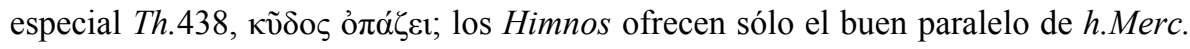

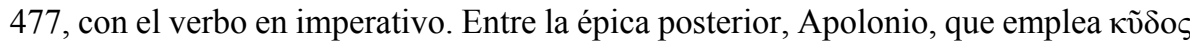
en once ocasiones, lo hace sólo en tres de ellas en sede semejante ${ }^{38}$, Nonno ofrece una

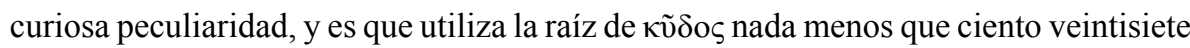
veces, pero sólo en $D$. XL 217, imitación de Il. XXII 393, aparece esa palabra, situación que resulta un poco menos exagerada en Quinto de Esmirna, que entre ciento

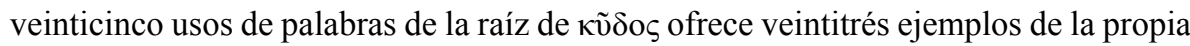
palabra, de los cuales sólo son comparables al nuestro III 197, IV 577 y VII 566, que

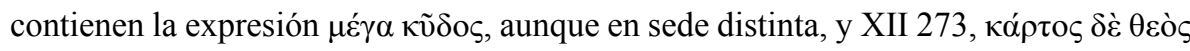

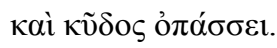

34 Podría ampliarse hasta la trocaica, incluyendo $\theta \varepsilon$ ćs, pero creemos preferible reducirla a los términos propuestos, pues si en la épica homérica se cita al dispensador de esa fuerza, se le menciona por el nombre (vid. Il. I 279, etc.)

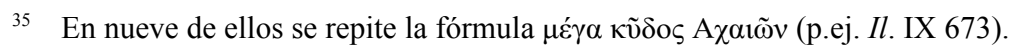

36 En su forma ỏ $\pi \alpha ́ \sigma \sigma-$ son semejantes a la nuestra diecisiete de sus veinticuatro ejemplos.

37 Th. 433; 438; Op. 313; Sc. 339; fr. 75, 19.

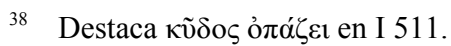


En la literatura de los siglos VIII-V los ejemplos son muy escasos, y la falta de empleo de formas del verbo ó $\pi \alpha ́ \zeta \omega^{39}$ es un indicio de lo que sucede con la cita en su conjunto. En todo ese período sólo puede mencionarse un uso cercano en dos ejemplos de Solón (fr.19.5 y 31.2, en los que se combinan sustantivo y verbo), y sólo Píndaro, en once ocasiones no comparables a nuestro ejemplo, y Baquílides, en un fragmento dudoso, utilizan el sustantivo.

Nos encontramos, en suma, ante unas palabras que aunque unidas no aparecen nunca en Homero, separadas y combinadas de diversa forma constituyen una expresión épica muy habitual, la de la concesión a un héroe de la fuerza necesaria para realizar hazañas portentosas. En ese sentido, la parodia y la burla del verso aristofánico es manifiesta y cabe pensar incluso en un falso epicismo, un invento de Aristófanes que ha unido palabras épicas de diversa procedencia para formar un conjunto que imita paródicamente dicho género. En otro orden de cosas, nos encontramos ante un ejemplo en el que Aristófanes se convierte prácticamente en el único autor de la época que estudiamos que conserva, aunque sea para ridiculizarlo, un homerismo.

\section{Eq. 433, $\quad \kappa \lambda \alpha ́ \varepsilon เ v \sigma \varepsilon \mu \alpha \kappa \rho \alpha ̀ ~ \kappa \varepsilon \lambda \varepsilon v ́ \sigma \alpha \varsigma$}

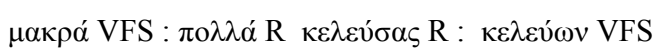

Según los escolios, $\mu \alpha \kappa \rho \alpha ̀ ~ \kappa \varepsilon \lambda \varepsilon v ́ \sigma \alpha \varsigma$ es una expresión antigua del ático que manifiesta el desprecio del superior hacia el inferior. Las variantes textuales señaladas, equivalentes tanto desde el punto de vista del contenido como del de la métrica y presentes asimismo en alguno de los paralelos que señalaremos, indican que el tópico era susceptible de expresarse de dos formas distintas ${ }^{40}$.

Aunque la mayoría de los comentarios modernos consultados no lo indica, se trata de una expresión de raíz claramente homérica que Aristófanes carga de comicidad al mencionar la orden, $\kappa \lambda \alpha ́ \varepsilon ı v^{41}$. Por otra parte, hay variantes textuales entre la frase de

39 Su ausencia es completa en los trágicos y entre los líricos más "homéricos" apenas si cabe mencionar cinco ejemplos en Píndaro y uno en Baquílides. El carácter épico del verbo es claro.

40 Nos hallaríamos, probablemente, ante variantes de origen rapsódico, una de las formas más frecuentes de modificación de un texto por la tradición indirecta, véase M. Van der Valk, Researches on the text and scholia of the Ilias II, Leiden, 1964, pp. 264-369, especialmente 266 ss. Con distinto orden de palabras, pero sin variantes textuales similares a las de este ejemplo,

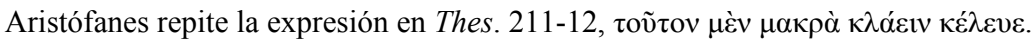

${ }^{41}$ Cuyo alejamiento del modelo homérico se demuestra por la imposibilidad de su inclusión en el ritmo dactílico, lo que no es problema con las palabras finales. 
Aristófanes y el texto de Homero que probablemente son de origen rapsódico: estaríamos ante una misma noción, expresada de dos formas equivalentes que han tenido diferente fortuna en la tradición manuscrita de los autores que la emplean.

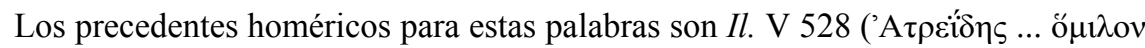

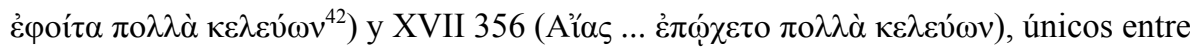
los numerosos ejemplos del verbo 'ordenar' en los que encontramos un complemento de género neutro, posiblemente con valor adverbial, como en el verso aristofánico. En estos ejemplos, además, ese complemento es el único, lo que quiere decir que no se menciona cuál es esa orden que con tanta insistencia dan los héroes, y en esto radica precisamente la comicidad de la parodia aristofánica, pues si el público reconocía la procedencia homérica de la mención de la orden, no dejaría de sorprenderse ante el contenido de la misma, "que te vayas a hacer muchas y buenas", una expresión vulgar, impropia del contexto épico al que apunta el resto de la frase: una carcajada segura.

La épica no homérica ofrece ejemplos comparables en los Posthomerica de Quinto

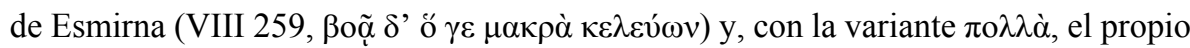

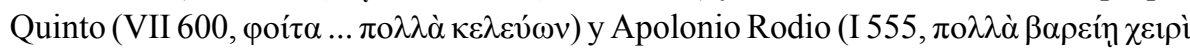
$\kappa \varepsilon \lambda \varepsilon v \dot{\omega} \omega v)$.

En la literatura de los siglos VIII-V apenas podemos mencionar un ejemplo en

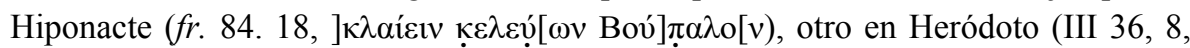

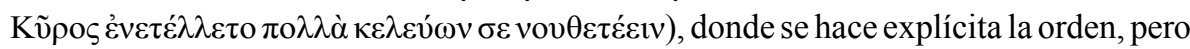
no tiene la carga de ridiculez del ejemplo aristofánico, y otro en Platón, también con

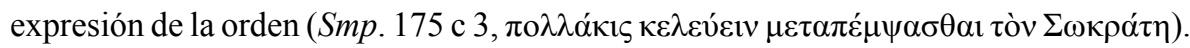

Estamos, en resumen, ante un homerismo claro, escondido en una frase aparentemente vulgar.

\section{Los versos de Trigeo y el Niño 1 en Pax 1270-87.}

Tras él éxito de su viaje al cielo para rescatar a Paz y devolverla a la tierra, Trigeo prepara un banquete. A las puertas de su casa, algunos mozalbetes, hijos de personajes que participan en el mismo, pronuncian versos que permiten identificar al padre de cada cual. El primero de ellos se arranca con un recitado de fuerte apariencia épica, tanto por el tema como por el contenido, que dará lugar en su momento a la identificación del niño como hijo de Lámaco y al consiguiente rechazo del mismo por Trigeo, que lo considera inapropiado por lo belicoso a sus propósitos actuales y a la situación de calma que se ha logrado gracias a él. Para el análisis de esta escena parece oportuno dividirla

42 Obsérvese que el texto de Homero ofrece las palabras que son variantes en Aristófanes y viceversa, cf. el aparato crítico de nuestra Ilíada II. Cantos IV-IX, Madrid, CSIC, 1998. 
en tres secciones: la primera, dedicada al v. 1270; la segunda a los vv. 1273-76, dividida a su vez en dos partes; y la tercera, que comprende los vv. 1280-87, dividida en otras tres.

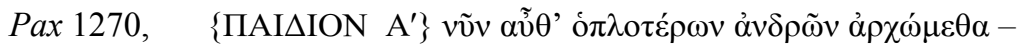

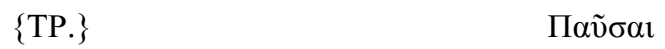

Como señalan los escolios, las palabras del niño coinciden con el comienzo de los Epígonos, poema épico del ciclo tebano ${ }^{43}$ que ellos atribuyen a un Antímaco, que necesariamente ha de ser el poeta de Teos que alcanzó su cima en el año 753 a. $C^{44}$, a nombre del cual aparece, en efecto, en las ediciones modernas ${ }^{45}$, pero que el Certamen entre Homero y Hesíodo y ciertos testimonios antiguos ${ }^{46}$ hacían, aun con dudas, obra de Homero, verdadero cajón de sastre de toda la poesía épica arcaica. Que Aristófanes piense en este momento como autor de ese verso en Antímaco o en Homero (a quien él también considera autor de casi toda la poesía épica) no importa demasiado. Es claro que el verso sería reconocido por el público, que su recitación haría trasladar la imaginación de todos al terreno de lo épico y que el $\pi \alpha \tilde{\sigma} \sigma \alpha \iota$ de Trigeo que lo cierra pronunciado, sin duda, con una inflexión de voz tan distinta del resto como pudiera el actor encargado de ese papel -, en lugar del esperado Moṽ $\sigma \alpha$, auténtico final del verso de los Epígonos, provocaría más de una risotada.

El tono épico del verso es manifiesto, y resulta extraño que ni Coulon, que no comenta los posibles homerismos del pasaje completo, ni Platnauer ${ }^{47}$, que lo hace ocasionalmente, señalen los paralelos. La exhortación a principiar el canto (no importa la deformación final de Trigeo) es usual en ese género, como puede verse en numerosos

43 Relataba la conquista de Tebas por la generación de los hijos de los siete adalides que, con Polinices a la cabeza, protagonizaron el fallido intento de tomar esa ciudad que refleja el mito de los Siete contra Tebas. El poema, del que apenas conservamos más fragmentos que estos versos de Aristófanes (v. A. Bernabé, ob. cit. pp. 29-32, T. W. Allen, Homeri Opera vol. V, Oxford, 1947 (corr.) pp. 115-6) era, al decir de Pausanias (IX 9, 2), el más bello del ciclo, a excepción de Ilíada y Odisea.

44 En el tercer año de la sexta Olimpiada, según Plutarco, Rom. 12, 2.

45 El verso corresponde con el fr.1 en la edición de Bernabé y en la de Allen, si bien este último no hace mención expresa del autor del poema. A mi entender, Aristófanes no debía de estar muy preocupado por esos distingos de atribución de autor, más propios de filólogos: Homero y la épica son para él la misma cosa, y, aunque eso no quiere decir que su opinión fuera acertada, cuesta creer que pudiera hacer gala de ella si su público no la compartía en mayor o menor medida.

46 Certamen 258-59; Heródoto IV 32. Respecto a la cronología relativa entre Aristófanes y el Certamen, véase más adelante, $n .62$.

47 M. Platnauer, Aristophanes. Peace, Oxford, 1964. 
Himnos Homéricos (p. ej. h. Cer. 1, h. Hom. 28. 1, etc.) y en los vv. 1-36 de la Teogonía y presenta un lejano paralelo en el comienzo de las elegías de la colección teognídea (v. 2). En cuanto a la expresión ó $\pi \lambda \mathrm{\alpha} \tau \dot{\varepsilon} \rho \omega \nu ~ \alpha ̉ v \delta \rho \tilde{v} v$, encontramos paralelos épicos en Homero y en la épica posthomérica ${ }^{48}$.

En resumen, Aristófanes introduce en boca del primer niño, ridiculizándolo en su final, el comienzo de los Epígonos. Es dudoso si con ello pretende hacer pensar a su auditorio en Homero, pero la inclusión de semejante verso, épico en su conjunto y en sus elementos, evocaría sin duda el mundo de referencias propio de ese género literario. Por otra parte, nuestro poeta es el único testigo entre los siglos VIII y V de esas expresiones épicas.

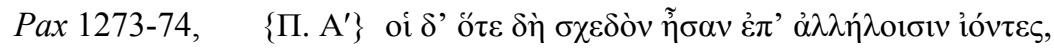

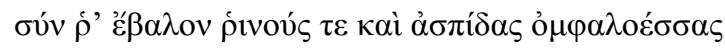

$$
\dot{\alpha} \sigma \pi i \delta \alpha \varsigma \cdot \dot{\alpha} \sigma \pi i \delta \delta \varsigma \mathrm{R}
$$

Versos así ofrecen pocas dudas acerca de la intención de Aristófanes de aprovecharse de Homero para sus fines. Tan belicosos hexámetros hacen pensar en las batallas de la Ilíada. De hecho, el niño que los pronuncia será enseguida (v. 1290) identificado como hijo de Lámaco. Los dos hexámetros conforman una frase de sentido completo y en todo o en parte repiten palabras de Homero, pero no hay ningún pasaje en los poemas de éste en el que aparezcan exactamente así, y ésa puede ser la razón que hace afirmar a Platnauer que $\operatorname{Pax} 1272-76$ es un centón homérico, para el que señala algunos de los paralelos que se mencionan a continuación. Digamos, por último, que ni en el resto de la épica ni en ningún autor de los siglos VIII-V encontramos huella alguna de estas palabras y que sólo Aristófanes lo hace. Veamos los precedentes homéricos:

Pax 1273 coincide exactamente con un verso homérico doce veces repetido, todas ellas en la Ilíad ${ }^{49}$; por su parte, el v. 1274 está formado de la unión de dos hemistiquios documentados en Homero, aunque no formando parte del mismo verso:

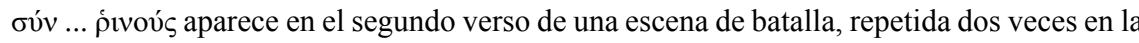

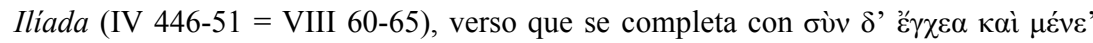
$\grave{\alpha} v \delta \rho \tilde{\omega} v^{50}$. Es digno de mención que el primer verso de esa escena de combate empieza

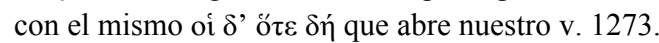

48 Il. III 108; A.R. I 192 y Q.S. V 156.

49 III 15, V 14, 630, 850, VI 121, XI 232, XIII 604, XVI 462, XX 176, XXI 148, XXII 248 y XXIII 816.

50 Lo que da a los paralelos homéricos y al comienzo de Pax 1274 cierta semejanza con el

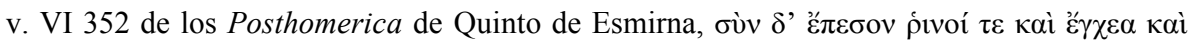
$\tau \rho v \varphi \alpha ́ \lambda \varepsilon ı \alpha 1$. 


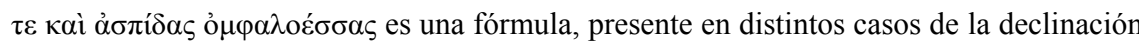
diez veces en la Ilíada y una en la Odisea ${ }^{51}$. Conviene señalar su presencia, en caso nominativo, en los vv. Il. IV 448 ( = VIII 62) integrados en la escena de batalla que contiene nuestro primer hemistiquio.

Veamos esta segunda parte del verso con más detalle:

En principio, la fórmula declinable $\alpha \sigma \pi i ́ \delta \alpha \varsigma$ ỏ $\mu \varphi \alpha \lambda o \varepsilon ́ \sigma \sigma \alpha \varsigma$ es susceptible de ocupar en el hexámetro tanto la posición inicial como la final, pero en todas sus apariciones,

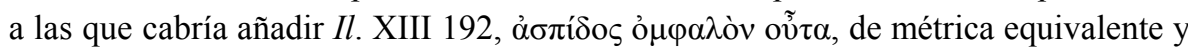
sonido muy similar ${ }^{52}$, está en final de verso, como en el ejemplo aristofánico. En esa

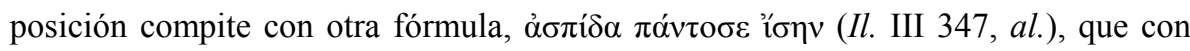
quince ejemplos es aún más frecuente que la nuestra.

En todos los ejemplos (incluyendo Il. XIII 192), el pie anterior, el tercero, es un

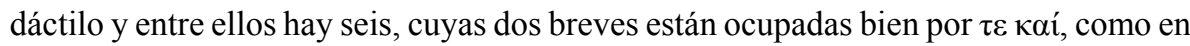

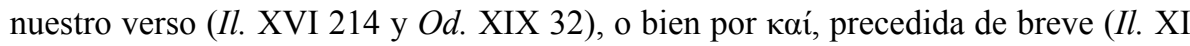
457, XII 161, XIII 264 y XIX 360).

Nos hallamos, en suma, ante un ejemplo claro de homerismo conservado exclusivamente por nuestro poeta y sólo la falta de la mención explícita del nombre de Homero justifica que no incluyéramos este ejemplo en el trabajo que dedicamos a las citas directas. No obstante, hemos dicho ya que la cita no es completamente literal, ya que, aunque en cada una de sus partes las palabras de Aristófanes están en Homero, no lo están nunca reunidas de esa manera: algo semejante a lo visto ya en el ejemplo de $E q$. 200. En ese sentido resulta especialmente notable el caso de los dos hemistiquios que componen el v. 1274. Que aparezcan en dos versos consecutivos de la Ilíada, IV 447 y 448 ( = VIII 61 y 62), sugiere la posibilidad de una variante de número de versos en el texto homérico, una cita condensada de dos versos en uno, cuyo sentido completo es perfectamente adecuado al tono general del género épico; es más, tal como los presenta Aristófanes, ofrecen una secuencia de contenido más lógica en sí y más parecida a otros pasajes épicos similares que la del texto de nuestras ediciones de Homero $^{53}$; sin embargo, no podemos saber si la secuencia de versos que presenta Aristófanes es producto de una deformación voluntaria de los versos de su modelo en busca de la sorpresa cómica o si refleja la existencia en su época de variantes de número de versos para este pasaje respecto al texto iliádico comúnmente aceptado. En mi opinión, no obstante, el hecho de que sólo en esos dos versos iliádicos, IV 447 y 448 (= VIII 61 y

51 Il. IV 448, VI 118, VIII 62, XI 259, 424, 457, XII 161, XIII 264, XVI 214, XIX 360, Od. XIII 192.

52 Añádase también $I l$. XXII 111, que presenta los integrantes de la fórmula separados.

53 Cf. nuestra nota a IV 446-51 en Homero. Ilíada II, ob. cit. 


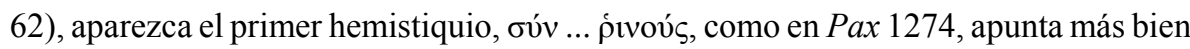
a la primera posibilidad: Aristófanes, para sorprender y hacer reír, deforma el modelo homérico, haciendo de dos versos uno solo con el principio del primero y el final del segundo.

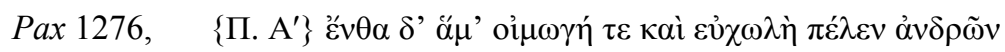

Tras la interrupción de Trigeo, a quien no le satisfacen las alusiones a escudos recién recuperada la paz, el niño vuelve a la carga con un nuevo hexámetro homérico, que está (es el v. 450 (=VIII 64) de Il. IV) dentro de la escena de guerra citada en el ejemplo anterior y es ejemplo único del verso en Homero. Este hecho refuerza, en mi opinión, la posibilidad que estamos discutiendo de que Aristófanes invente para sorprender al público o conozca una variante más breve para todo este pasaje que la de nuestra Ilíada y no sólo para 1274. Recuérdese que la escena de batalla repetida (IV 446-51 = VIII 6065) comienza por el mismo oi $\delta$ ' ö $\tau \varepsilon \delta \eta ́$ que nuestro v. 1273.

Como en el ejemplo anterior, nos hallamos ante la conservación exclusiva por Aristófanes de un verso que sólo se documenta en Homero. Con todo, puede apuntarse algún verso parecido en la épica posterior, concretamente en Quinto de Esmirna (XIII

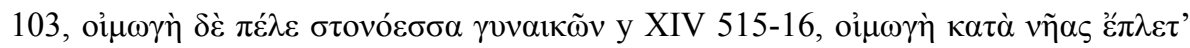
$\dot{\alpha} \pi \circ \lambda \lambda v \mu \varepsilon ́ v \omega v)$.

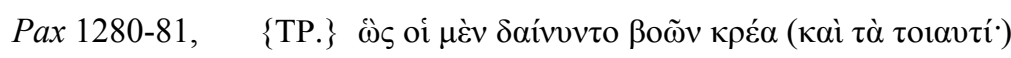

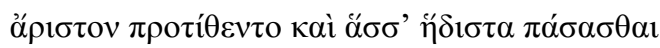

El verso 1280 - con el final que presenta en el 1283, donde se repite -, el 1283 y los vv. 107-108 del Certamen entre Homero y Hesíodo, cuyo primer verso presenta una va-

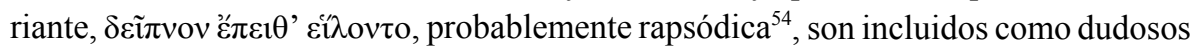
entre los fragmentos de los Epígonos (fr. 6 Bernabé). Sobre la autoría de este poema hemos hablado al comentar Pax 1270 y aún hemos de hacerlo en la cita siguiente.

Tras completar su primer verso con palabras propias, que respetan, no obstante, la secuencia métrica del hexámetro, como hizo ya en el v. 1270, Trigeo se siente inspirado y recita, como si fuera épico, un verso inventado por él, más adecuado a sus intenciones del momento. El resultado es un hexámetro correctamente construido pero de muy escasa relación con posibles modelos homéricos. Vayamos por partes:

Respecto al v. 1280, hay que decir que entre los muy numerosos ejemplos de

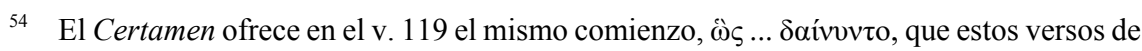
Aristófanes. 


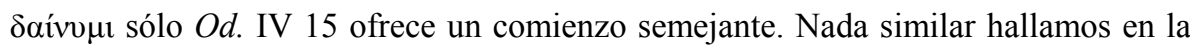

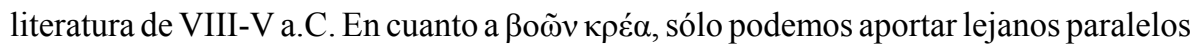

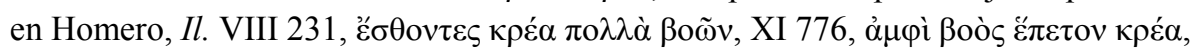

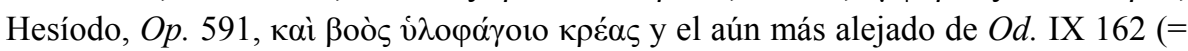

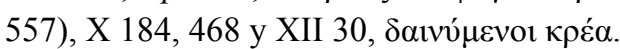

En cuanto al v. 1281, se trata de un hexámetro que no tiene el aire de Homero. Y no es que en sus poemas falten versos que Trigeo pudiera recitar en este contexto para adornar con la autoridad del poeta épico sus propósitos de darse un banquete; a título

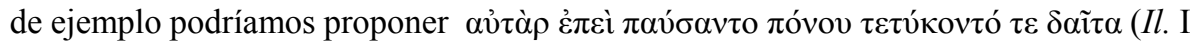
467 (= II 430, VII 319), muy semejante a Od. XVI 478 (=XXIV 384)) o bien $\delta \varepsilon i ̃ \pi v o v$

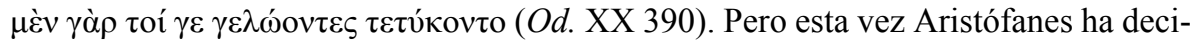
dido utilizar el ropaje externo de la épica para vestir unas palabras que carecen por completo de su empaque, una inadecuación de forma y contenido que por fuerza habría de resultar graciosa. Es un verso de paternidad completamente aristofánica y para encontrar posibles precedentes es preciso desglosarlo palabra por palabra.

La alusión al desayuno parece coloquial; sin embargo Il. XXIV 124 y Od. XVI 2

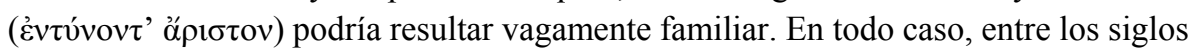
VIII y V sólo Ananio, un yambógrafo, documenta esa palabra (fr. 5.2).

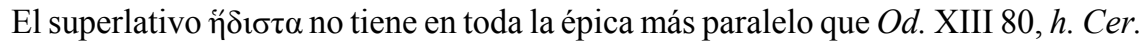
13 y h. Ap. 169, pero sí ofrece numerosos ejemplos en la literatura de los siglos VIII-V

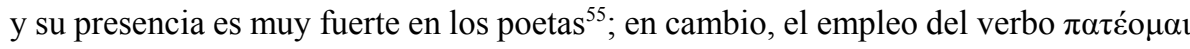
en sus diferentes formas es más frecuente en la épica que fuera de ella ${ }^{56}$. En Homero los versos que contienen este verbo suelen incluir la mención del alimento que se consume, y aunque el conjunto no tiene un lugar fijo en el verso, lo más habitual es que vaya al final del mismo ${ }^{57}$, situación que se repite en términos generales en los demás ejemplos del verbo en la épica ${ }^{58}$. El conjunto de la intervención de Trigeo es, en resumen, una mezcla cómica de un primer verso claramente épico y otro que, aunque en sus

55 En Eurípides, p. ej., hay veintidós ejemplos.

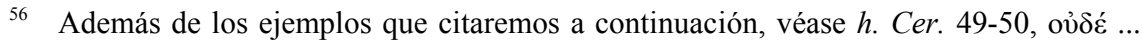

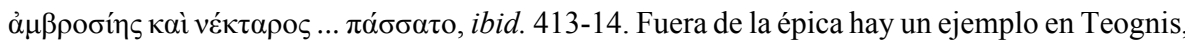

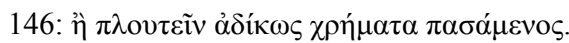

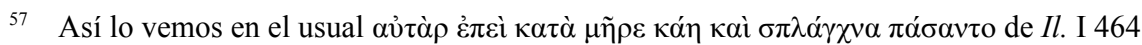
(= II 427, Od. III 461, XII 364) y en otros ejemplos como Il. IX 487, Od. I 124, IV 61 y IX 93. Lo hallamos también en otras posiciones del verso en Il. XIX 160-61, XXIV 641, Od. III 9 y X 384.

58 En final de verso lo encontramos en A.R. II 1177, Nic. Ther. 663, Opp., H. I 26, II 452, III 523 y Opp., C. III 260; en otras posiciones del verso, en Hes., Th. 642, A.R. I 1072, III 790, IV 21 y Opp., $H$. II 473. 
componentes individuales tiene precedentes en ese género, carece en conjunto del tono solemne que a su forma métrica le correspondería en principio y adquiere un sentido ridículo. Inmediatamente la intervención del Niño 1 volverá a sugerir ese mundo de referencias al que Trigeo parecía aludir en su primer verso.

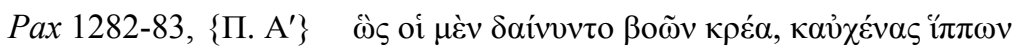

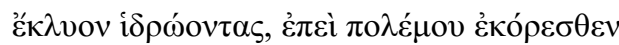

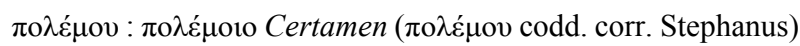

Sin la deformación de Trigeo, el Niño recita los dos versos que, como dijimos en el ejemplo anterior, figuran en las ediciones modernas entre los fragmentos dudosos ${ }^{59} \mathrm{de}$ los Epígonos. Es importante señalar que en esta ocasión, a diferencia de lo que pasaba con el v. 1270, ni los escolios ni el Certamen mencionan los Epígonos como fuente de estos versos ${ }^{60}$. Ya hemos dicho también que el Certamen presenta una variante para el primer verso y a ella hay que añadir la que citamos supra en el aparato crítico de esta cita.

Desglosados en sus componentes y realizado su rastreo en los lugares de costumbre, a saber, Homero y la épica, por una parte, y la literatura de los siglos VIII-V, por otra, encontramos lo siguiente ${ }^{61}$ :

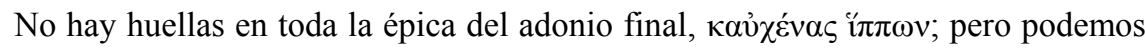
citar expresiones parecidas en Homero y fuera de Homero $^{62}$; y entre los siglos VIII y

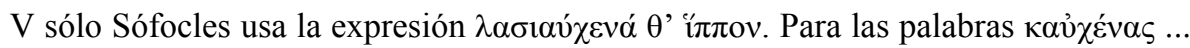

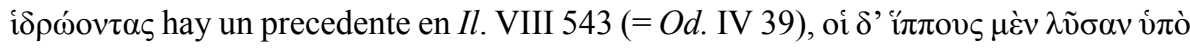

59 Que los editores modernos adscriban, aun con dudas, estos versos a los Epígonos ( $f$ r. 1 de ese poema) quizá pueda justificarse por su cercanía con $\operatorname{Pax} 1270$ y por su ausencia entre los versos de Homero.

${ }^{60}$ El Certamen los incluye en un pasaje que recuerda el agón de Esquilo y Eurípides en las Ranas: Hesíodo y Homero compiten, recitando cada uno un verso, primero Hesíodo, lo que supondría que en este caso Pax 1282 sería suyo y Pax 1283 de Homero, lo que quiere decir que si estos versos fueran de los Epígonos, el Certamen haría autores de ellos a dos poetas diferentes.

${ }_{61}$ Omitimos las referencias a la parte del v. 1282, que fueron hechas ya al analizar el v. 1280.

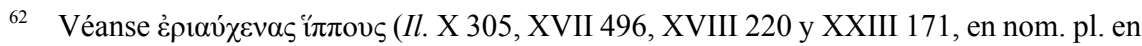

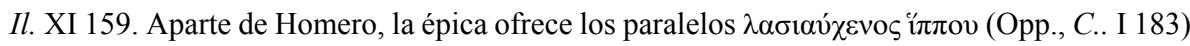

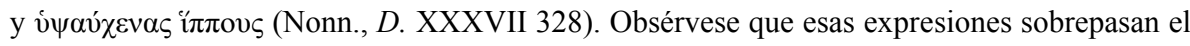
volumen prosódico del supuesto verso de los Epígonos transmitido por Aristófanes y el Certamen. 
$\zeta v \gamma o \tilde{~ i \delta \rho \omega ́ o v \tau \alpha \varsigma . ~}$

En el segundo verso nada, excepto lo recién apuntado, puede aducirse como precedente para sus primeras palabras, y la situación no es mejor en el resto, carente asimismo de paralelos exactos. No obstante, pueden aportarse ejemplos del uso del verbo con régimen en genitivo, como en el verso de Aristófanes, con palabras de sentido concreto indicando el alimento con el que se sacian, o en dativo instrumental. Entre ellos consideramos especialmente interesantes aquellos cuyo complemento tiene alguna relación con el ámbito de la guerra, la palabra que constituye el complemento del verso que analizamos.

Homero ofrece siete ejemplos con esas características. En cuatro de ellos (Il. XI 562, XIX 167, Od. XIV 456 y XVIII 172) el complemento es una palabra de sentido

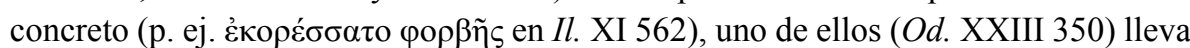
un complemento de sentido menos material y en los dos restantes (Il.XIX 221 y XX 2) pertenece al ámbito de la guerra ${ }^{63}$. La similitud con nuestro verso es, no obstante, mínima.

Fuera de Homero, en la épica el complemento es una palabra de sentido concreto en un verso del Himno a Deméter (v. 175, un ejemplo muy parecido a Il.XI 562, ya citado), en los tres ejemplos de Apolonio (II 307, 1149 y 1227), en cuatro de los cinco ejemplos de Nicandro $^{64}$, en los dos de Nonno (D. XVII 67 y XXXV 279) y en cuatro (VI 96, VII 707 (= XIV 336), VIII 406 y IX 489) de los seis de Quinto de Esmirna, que ofrece dos usos con complemento más bien abstracto (III 521 y V 599). Sólo el Escudo pseudohesiódico presenta en sus tres empleos del verbo (vv. 346, 433 y 459), como el verso de Aristófanes y los dos ejemplos iliádicos citados supra, un complemento perteneciente al campo semántico de la guerra.

Por su parte, en la Literatura de los siglos VIII-V no hay paralelos exactos. Ni siquiera cabe mencionar en ese período la presencia de ejemplos como los recién mencionados con complementos relacionados con la guerra. Los usos de ese verbo suelen presentar complementos de sentido concreto ${ }^{65}$, excepto un ejemplo de Teognis, $\pi \lambda$ ov́

Del análisis de los dos versos de esta cita surge una conclusión evidente: constituyen una expresión única, ajena a la tradición, aunque para algunas palabras y expresiones contenidas en ellos pueda apuntarse algún que otro paralelo lejano. Y en esas circuns-

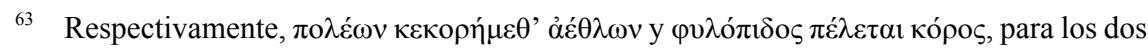
últimos grupos,.

${ }^{64}$ Ther. 285; Alex. 63, 351 y 360 . El sentido del complemento es menos material en su otra

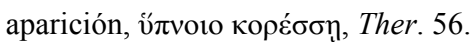

65 Thgn. II 1249, 1269; Aesop. 164. 1, 1; Hdt. I 213 y 214. 
tancias cabe preguntarse por su autoría. ¿Son, como afirma el Certamen, versos de Hesíodo y Homero? ¿Formaron parte, como aceptan aun con dudas los editores modernos, de los perdidos Epígonos, fuera quien fuese el autor de éstos? ¿O son, simplemente, un invento de Aristófanes que ha configurado dos versos de apariencia completamente épica, sacando sus integrantes de aquí y de allí?

Y aún hay una segunda cuestión que plantean estos versos, la discrepancia textual entre Aristófanes y el Certamen y la relación cronológica entre ellos. Vamos a abordar aquí esta cuestión y dejaremos para el siguiente ejemplo, con el que acaba este grupo de citas, el problema de la autoría antes mencionado.

En ese sentido es preciso afirmar que pese a que Platnauer en su comentario a los vv. 1280-81 de esta comedia dice que Aristófanes ha tomado del Certamen el principio de sus versos, esa obra suele datarse con posterioridad a nuestro cómico, lo que significa que si hay alguna relación de dependencia entre ellos sería el Certamen el que habría introducido cambios sobre el modelo de Aristófanes ${ }^{66}$. Sin embargo, es preciso recordar que la lectura del comienzo de $\operatorname{Pax} 1280$, repetido en 1283, no tiene más paralelos que $O d$. IV 15 y el más lejano de $O d$. IX 162, etc., en tanto que la variante del Certamen está algo más representada en la tradición épica, con ejemplos en Homero,

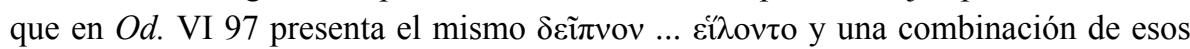
mismos verbo y sustantivo en otras cuatro ocasiones (Il. II 399, VIII 53, Od. IX 86 (= X 57) y XVII 176), y fuera de Homero en un único ejemplo del mismo tipo que estos últimos paralelos homéricos recién citados ${ }^{67}$.

Es decir, las dos variantes cuentan en los poemas homéricos y en el género épico con posibles precedentes más o menos exactos, y en esas condiciones, si queremos defender que Homero late en ese verso, no se le puede otorgar mayor autoridad a una variante que a la otra, sino que, como ya apuntábamos, lo correcto sería interpretarlas

66 La cronología más alta la dan A. Pérez Jiménez y A. Martínez Díez, Hesiodo, Madrid, 1983, que piensan en V-IV a.C.; para F. Rodríguez Adrados (en J.A. López Férez (ed.), Historia de la Literatura Griega, ob. cit. p. 68) es seguramente de IV a.C. y el Canon del TLG lo sitúa entre III antes y II d.C. Por su parte, West, «The contest of Homer and Hesiodus», CQ 17, 1967, pp. 433-50 y V. di Benedetto, «Aristophanes, Pax 1282-3 e il Certamen tra Omero e Esiodo», Rend. Acad. Linc. ser VIII 24, 1969, pp. 161-65 difieren en el sentido de que mientras West niega cualquier relación voluntariamente establecida por Aristófanes entre estos versos y Homero y Hesíodo, para di Benedetto, Aristófanes habría innovado respecto al Certamen, al darle los dos versos a un solo personaje (lo que, de paso, supone concederle mayor antigüedad). Nosotros pensamos más bien que el Certamen es posterior a Aristófanes y que, aunque hubiera sido al contrario, no cabría hablar de innovación por parte de éste, sino, en todo caso, de deformación cómica.

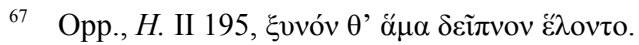


como rapsódicas, variantes libres entre dos expresiones alternativas de una misma acción, y de ser así no podrían utilizarse para determinar la cronología relativa de las dos fuentes que las transmiten.

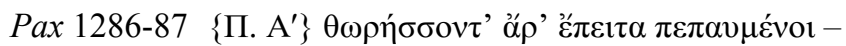 $\{\mathrm{TP}$.

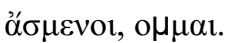

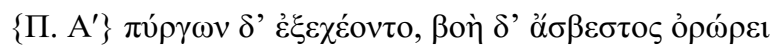

De nuevo el niño recita versos de apariencia épica - el primero de ellos interrumpido por el irónico comentario de Trigeo -, pero que, como veremos, carecen prácticamente de precedentes en ese género. Como los del ejemplo anterior, los versos son considerados, con dudas, parte de los Epígonos (fr. 7 Bernabé, cf. Allen p. 116), pero en este caso Aristófanes es la única fuente de los mismos. Vamos a buscar los posibles paralelos, descomponiendo los versos en sus integrantes:

No hay ningún ejemplo de $\theta \omega \rho \eta ́ \sigma \sigma o v \tau '$... ह̌́ $\varepsilon \varepsilon 1 \tau \alpha$, a pesar de que el verbo es muy frecuente en la poesía épica, pero no en el comienzo del verso, posición para la que sólo cabe mencionar el paralelo de Quinto de Esmirna (VIII 4). La sede más usual es el final de verso. Así se da en trece de los veinte ejemplos del verso en Homero, en la Teogonía hesiódica y en sus dos usos en la épica posthomérica ${ }^{68}$; puede afirmarse, en consecuencia, que su uso en esa sede es formular y en ese sentido resulta sorprendente que no sea su lugar en el verso en ninguno de sus diez usos en Nonno.

En cuanto a $\pi \varepsilon \pi \alpha v \mu \varepsilon ́ v o$, hay que decir que esa forma sólo aparece en Il. III 150 y precisamente en esa sede, pero con una diferencia importante, y es que en ese verso, como suele suceder en la mayoría de los numerosos ejemplos que el verbo presenta en Homero, un complemento aclara con qué se termina, cosa que no aparece en este verso. $\mathrm{Y}$ a diferencia de otras ocasiones en que nos hemos atrevido a proponer una forma de completar el verso que comentábamos (véase más arriba respecto a Pax 1281), no encontramos en ninguno de ellos el complemento que nuestro $\pi \varepsilon \pi \alpha v \mu \varepsilon ́ v o r$ podría llevar en el hipotético verso épico que recita el Niño 1 y que habría sido sustituido por el irónico comentario final de Trigeo ${ }^{69}$, ya que, como hemos dicho, Il. III 150 es el único ejemplo en todo Homero en el que una forma de ese verbo ocupa esa $\operatorname{sede}^{70}$.

68 De los veinte ejemplos de Homero sólo uno es de la Odisea (XII 227) y ocho de los trece ejemplos en que el verbo ocupa el final de verso aparece en la misma forma que en nuestro verso; los ejemplos posthoméricos corresponden a A.R. I 42 y a Opp., C. I 202.

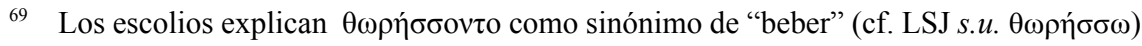
y tanto Van Leeuwen como Platnauer aceptan, acertadamente a mi juicio, ese sentido para este verso, al que consideran deformación de Il. VIII 53-54.

70 En el resto de la épica el verbo sólo aparece en esa posición en seis ejemplos, todos de 
Tendríamos pues, como otras veces, formas épicas empleadas en sede no épica, y ello, unido al posible doble sentido de $\theta \omega \rho \eta ́ \sigma \sigma \omega$ en este verso, refuerza la posibilidad de que el verso no sea de procedencia épica, sino una invención de Aristófanes.

En cuanto al v. 1287, si no es, como sugería Nauck ${ }^{71}$, deformación de Il. XVI 267,

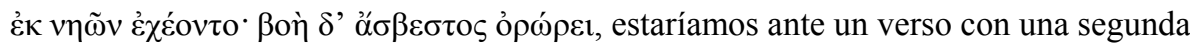
parte plenamente épica, pero cuya primera parte sería un completo invento de nuestro

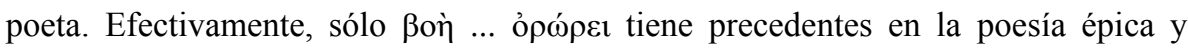
particularmente en Homero, en cuyos poemas esas palabras son una fórmula de final de verso $^{72}$, la misma posición que, aunque modificada, ocupa en sus dos únicos ejemplos de la épica no homérica ${ }^{73}$.

Concluido el análisis del grupo de citas de Pax 1270 ss., es momento de responder a la pregunta que dejamos planteada al comentar los vv. 1282-83. ¿Estamos ante la presencia de versos épicos auténticos - de los Epígonos concretamente, sea este poema obra de Homero o de Antímaco - o ante unos versos donde lo épico es sólo aparente y son una invención paródica de Aristófanes, que ha reunido palabras épicas bien documentadas, colocándolas en posiciones del verso ajenas a lo habitual en ese género $^{74}$ ? El problema, en realidad, atañe más a los vv. 1280 ss. que a los anteriores, pues tanto para 1270 como para $1272-73$ y 1276 hemos podido encontrar buenos paralelos que permiten referirlos al mundo de Homero y la épica. Otra es la situación para los versos 1280-87, que hemos distribuido en tres $\operatorname{citas}^{75}$. En rigor, la épica ofrece ejemplos similares por el contenido y por la posición de las palabras en el verso sólo

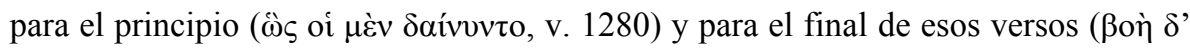

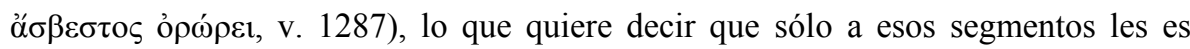
imputable sin problemas el carácter de cita épica u homérica por parte de Aristófanes; pero no pasa lo mismo con el resto, que parece hecho por medio de la reunión caprichosa de palabras épicas en lugares del verso extraños para esas palabras cuando aparecen en la épica.

Pese a todo, las ediciones modernas de poesía épica atribuyen, aunque con dudas, es-

Apolonio: III 418, IV 714, 775, 779, 882 y 1630.

${ }^{71}$ Apud Bernabé, ob. cit. p. 31. La referencia a ese verso es señalada también por Platnauer.

72 Véase Il. XI 500, 530 (levemente modificada), XIII 169 (= 540), XVI 267; en Od. XXIV 48 la modificación es mayor.

73 Pertenecen ambos a los Posthomerica de Quinto de Esmirna, IV 561, ßò̀ $\delta$ ' ảvò $\lambda \alpha$ òv ỏ

74 Algo semejante hemos visto en Eq. 200 y Pax 1273-74.

75 Aunque podrían reducirse a dos, ya que en el v. 1283 se repite el 1280 con un final más “auténtico". 
tos versos de Aristófanes a poemas épicos perdidos; pero la carencia de paralelos que hemos señalado en su análisis y el hecho de que nuestro poeta sea fuente única o casi única del presunto poema épico perdido nos induce a creer más bien que los versos son un mero invento de nuestro poeta y que nunca formaron parte de otro poema que $\mathrm{La} \mathrm{Paz}$.

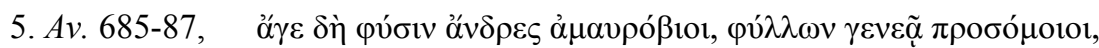

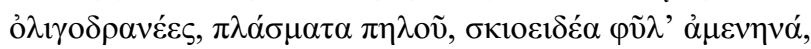

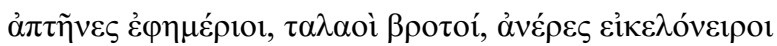

Dentro de un pasaje en tetrámetros anapésticos catalécticos (nos hallamos en la parábasis), el corifeo emplea para calificar a los seres humanos algunos adjetivos y expresiones que a primera vista podrían pasar por épicos. La presencia de dichas palabras en ese ritmo, en cuyo seno el dáctilo es un pie utilizable en casi cualquier posición y cuyas semejanzas generales con el ritmo dactílico son manifiestas, facilita notablemente la posibilidad de uso de formas épicas: de hecho estas palabras cumplen ese requisito; pero de todo el pasaje tan sólo podríamos pretender una segura proce-

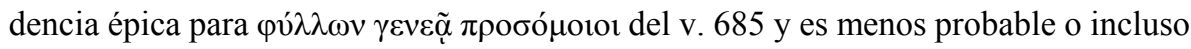
hay que rechazar la posibilidad por completo para el resto y posiblemente la mejor opción para alguno de los términos aquí usados sea pensar que estamos ante frases gnómicas y que como tales son objeto de profusa utilización por diversos géneros, lugares comunes no exclusivos de ninguno de ellos. Veámoslo en detalle:

Ni Homero, ni la épica, ni la literatura entre los siglos VIII y V usan jamás el

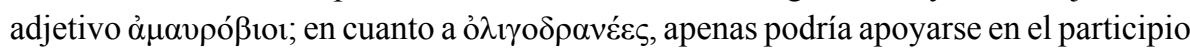

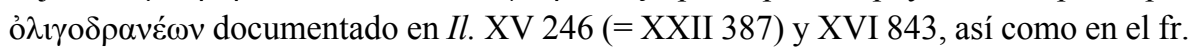

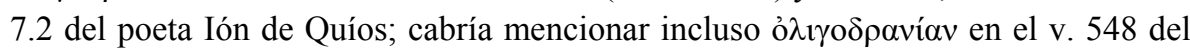
Prometeo de Esquilo.

La situación no es mucho mejor para la expresión $\sigma \kappa 10 \varepsilon 1 \delta \varepsilon \dot{\alpha} \alpha \varphi \tilde{v} \lambda$ ’ $\alpha \mu \varepsilon v \eta v \alpha ́$, ya que el primer adjetivo suele ofrecer en Homero la forma compuesta mediante el sufijo -oєı $\varsigma$ y el sustantivo que constantemente completa a $\alpha \mu \varepsilon v \eta v \alpha ́$ es $\kappa \alpha ́ \rho \eta v \alpha^{76}$, si bien el v. 352 del Himno a Deméter contiene el mismo grupo $\varphi \tilde{v} \lambda$ ' $\alpha \mu \varepsilon v \eta v \alpha ́$ que el verso de Aristófanes. Tampoco son observables posibles precedentes épicos para $\tau \alpha \lambda \alpha$ oì $\beta \rho o \tau o i ́ ;$ de hecho, no hay ejemplos de la primera de esas palabras en ninguno de los ámbitos que consideramos en este trabajo, donde lo que aparece es, o bien la forma simple, $\tau \alpha \dot{\lambda} \lambda \alpha \varsigma$, muy frecuente en la tragedia, pero no en expresiones tales que puedan hacer pensar en que ésta se ha tomado de ella, o bien en el compuesto $\tau \alpha \lambda \alpha \sigma i ́ \varphi \rho \omega v$. Sin paralelos exactos, aunque bien documentada, encontramos la calificación de efímero para el

76 Cuatro ejemplos, todos en la Odisea: X 521, parecido a XI 29 y X 536, parecido a XI 49. La expresión falta en la literatura de los siglos VIII-V a.C. 
género humano y la que lo compara con la inanidad de los sueños ${ }^{77}$. Con todo, se trata de expresiones sin paralelo exacto, que esta vez, dada su presencia en un pasaje fácilmente adaptable al ritmo dactílico, habría sido sencillo de conseguir. Ello nos induce a suponer que en estas palabras no hay indicios de cita $-\mathrm{y}$, por ende, de parodia - de palabras y expresiones homéricas o épicas concretas, sino ante la presencia en la comedia de una máxima bien conocida y con amplia representación en toda la literatura.

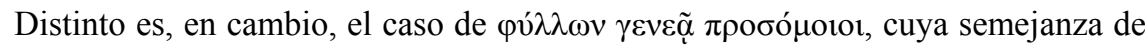
contenido con $I l$. VI 146, uno de los versos de Homero más citados en la literatura griega $^{78}$, es señalada por los escolios pero incomprensiblemente silenciada por Coulon. En el texto de Aristófanes esta expresión debe considerarse sin duda un homerismo, pues, de hecho, sólo en Homero dentro de la literatura de los siglos VIII-V encontramos, aparte del ya citado, posibles precedentes para esta expresión, lo que quiere decir que una vez más nuestro poeta es testigo prácticamente único de esa clase de expresiones ${ }^{79}$. Podrían mencionarse expresiones parecidas en $I l$. II 800, $\lambda i ́ \eta v$ yò $\rho$

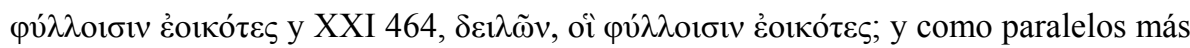
alejados, los vv. 147-48 de $I l$. VI, donde se desarrolla el símil y, muy parecidos a ellos, Il. II 468, Od. IX 51, Mimnermo 2.1 y Píndaro, Pyth. 9, 46. El motivo es, en todo caso, frecuente en el género épico, como lo prueban ejemplos de Quinto de Esmirna (I 345 y IX 503-4), Nonno (D. III $249^{80}$ ) y Apolonio (IV 216). Por ello, a pesar de que ni

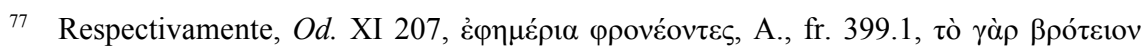

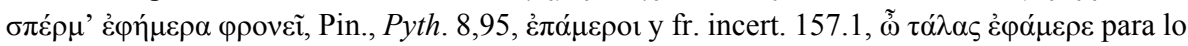

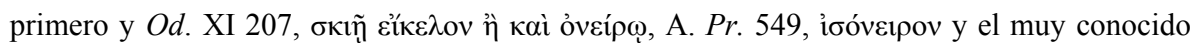

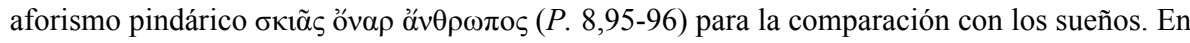
la misma línea, aunque en forma algo diferente, cabe aún mencionar dos ejemplos en Sófocles, Ai. 125-26 y $P$ h. 946-47.

78 Véase el aparato de referencias de nuestra edición de la Ilíada de Homero, ob. cit., vol. II.

79 Entre los siglos VIII y V sólo tenemos la cita literal de Il.VI 146 por Simónides de Ceos (fr. 8 de M.L. West, Iambi et elegi Graeci, vol. 2, Oxford, 1972). Hace tiempo, siguiendo una conjetura de Bergk que reflejaba un claro intento de defender para Homero la datación más alta posible, la cita se le atribuía al yambógrafo Semónides de Amorgos, cuya cronología es dudosa, pero, en cualquier caso, anterior al lírico de Ceos. Por otra parte, Clemente de Alejandría (Strom. VI 2, 5) afirmaba que el verso en cuestión era de Museo, de quien lo habría tomado Homero, lo cual, unido a la presencia del desarrollo del motivo que ese verso inicia (que se hace en los versos inmediatamente siguientes) en otros pasajes de Homero y fuera de Homero (por ejemplo, Mimnermo y Píndaro, a quienes nos referiremos enseguida), hace pensar que entre todos esos testimonios no hay relación de modelo y copia, sino que quizá todos reflejan independientemente un motivo tradicional, probablemente de carácter oracular, cf. nuestro Homero. Ilíada I, Madrid, 1991, pp. L-LI.

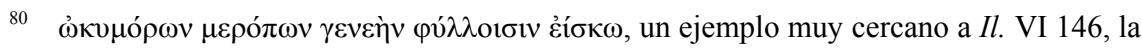


Homero ni la épica ofrecen un paralelo exacto para estas palabras, la frecuente presencia en ellos del motivo de la comparación entre la vida del hombre y la de las hojas nos hace afirmar que en esta ocasión hay una intencionalidad por parte del cómico de hacer pensar en Homero y la épica al introducir esas palabras en sus versos.

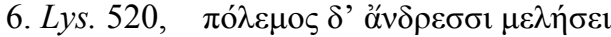

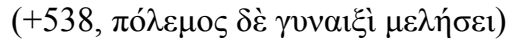

Remedando a su marido, que reivindica la actividad bélica como algo puramente varonil, Lisístrata pronuncia esas palabras que poco más adelante (v. 538) repetirá deformadas Cleonica, reclamando para las mujeres la participación en esas mismas actividades. Nos encontramos, como en el ejemplo anterior, dentro de sendos pasajes de ritmo anapéstico, tetrámetros catalécticos en 520, donde estas palabras ocupan el segundo hemistiquio, es decir, constituyen un paremiaco, y un breve sistema anapéstico que cierra precisamente el v. 538, otro paremiaco.

Las palabras del marido de Lisístrata reproducen las que le dirige Héctor a su esposa durante su breve visita a la ciudadela troyana (constituyen el segundo hemistiquio de Il. VI 492, desde la cesura pentemímeres hasta el final, y se repiten posteriormente, en igual sede pero contexto diferente, en XX 137). Los escolios señalan la procedencia homérica de ese hemistiquio y también lo hacen los comentaristas modernos ${ }^{81}$. Homero es, en efecto, el único poeta épico que emplea esa frase, y la combinación de esas tres palabras juntas no se da en la literatura de los siglos VIII-V más que en este verso de Aristófanes, aunque cabe citar un lejano paralelo en Jenofonte, Cyr. VI 2, 6, ö $\sigma \alpha$

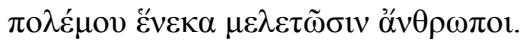

Si eliminamos una de las palabras de la cita, resultan dos posibles agrupaciones: por una parte, los hombres y su actividad; por otra, la guerra y sus exigencias. Respecto a la primera combinación, hay que decir que es casi exclusiva de Homero y su Odisea

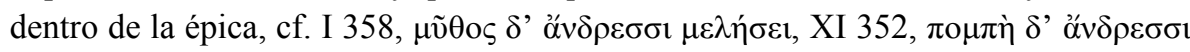

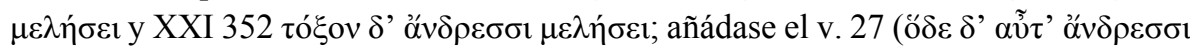
$\mu \varepsilon \lambda \eta ́ \sigma \varepsilon 1)$ del Himno Homérico a Dioniso. Los ejemplos prueban que, aun con cometidos diferentes, se trata de una expresión formular de final de verso. La literatura de los siglos VIII-V no ofrece sino dos ejemplos de esta combinación de palabras (Thgn. 612,

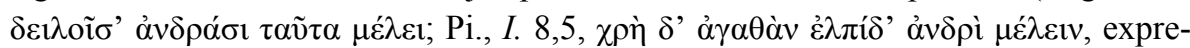

referencia homérica más próxima a este verso de Aristófanes, y que continúa en un sentido muy parecido al de los paralelos más lejanos de $O d$. IX 51, etc.

81 Véanse, entre otros, Coulon; F. Rodríguez Adrados, Aristófanes. Las avispas. Las aves. La paz. Lisístrata, Madrid, 1981; J. Henderson, Aristophanes. Lysistrata (ed. com.), Oxford, 1987 y A. López Eire, Aristófanes. Lisistrata, Salamanca, 1994. 
siones muy diferentes de la que estamos considerando.

En cuanto a la mención conjunta de la guerra y su atención, la épica sólo ofrece un

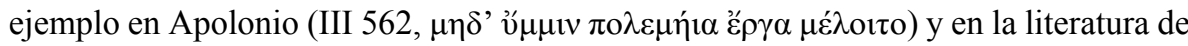
los siglos VIII-V todos sus ejemplos se encuentran en obras escritas en prosa ${ }^{82}$.

El v. 520 de Lisistrata nos pone una vez más ante la conservación exclusiva de un homerismo por parte de nuestro poeta, así como (v. 538) ante su deformación voluntaria con vistas a provocar la sorpresa y la risa de su público. A los escolios antiguos y a los numerosos comentaristas modernos que han señalado el paralelo del v. 520 con $I l$. VI 146 se les ha pasado por alto la fuerte comicidad que contiene su parodia un poco más adelante en boca de Cleonica: la aparentemente leve deformación que sobre el modelo

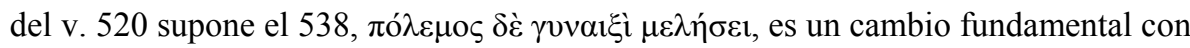
un efecto doblemente chocante. Por una parte, por la atribución a las mujeres, mediante palabras que respetan el ritmo de la épica, de cometidos que ésta les niega en absoluto ${ }^{83}$; por otra, por la muy diferente forma métrica ${ }^{84}$ de la parodia respecto al modelo. A la sorpresa de una afirmación inesperada se uniría el golpe de una secuencia rítmica inusitada, con el efecto cómico que cabría suponer.

\section{Conclusiones}

El análisis de los dos grupos de citas homéricas estudiados en este trabajo, a saber, parodias de situación y versos y miembros de versos homéricos, apoya con nuevos datos las conclusiones que se alcanzaron en el análisis de las citas directas, aunque sólo podremos considerarlas definitivas cuando se haya completado el análisis de todos los ejemplos. Hemos visto, en efecto, también en este trabajo, que Aristófanes tiene en Homero un referente universal para todo lo

82 Th. II 39, 1; Isoc. IV 86, 8; VII 82, 6; XI 15, 6; 15, 9; XII 168, 3; 217, 5; XV 293, 4; X. Eq. 11. 13, 2; Lac. 13. 2, 1; Cyr. 1. 6, 42; 8. 1, 38; P1. Lg. 865 a; Ti. 24 b.

${ }^{83}$ Las propias palabras de Héctor a Andrómaca son una amable invitación a que se ocupe exclusivamente de sus cosas. Mucho menos amables y más explícitas son las palabras con las que

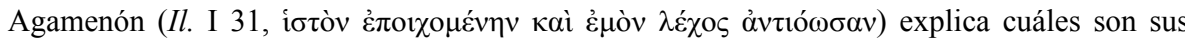
intenciones respecto a Criseida.

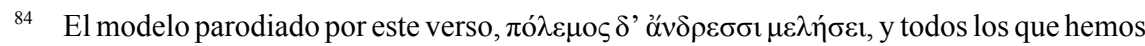
citado como parecidos a él por mencionar a la par a los hombres y sus cometidos, ocupan siempre la misma porción del verso: desde la cesura pentemímeres hasta el final, y su cuarto pie es un espondeo que respeta el llamado "puente bucólico", ya que la segunda larga de dicho espondeo pertenece a la misma palabra que la primera del quinto pie. En la parodia, en cambio, el segmento de verso es el mismo, pero el cuarto pie es un dáctilo, entre cuyas dos breves, además, hay un final de palabra. Incumple, pues, el respetadísimo "puente de Hermann". 
épico y que ese género le proporciona un filón del que sacar situaciones o palabras que en un momento pueden servirle para caracterizar una acción, un personaje, etc. La épica, en conjunto y en detalle, era, sin duda, un género bien conocido entre el público ateniense de finales del siglo $\mathrm{V}$, y cuando se comparara la vulgaridad del contexto cómico, tanto en situación como en palabras, con el tono elevado y el aura general de nobleza de la épica, tan bien conocidos por todos, forzosamente habría de producirse un contraste sorprendente y ridículo que provocaría la risa.En cuanto al número relativo de unas y otras, se observa que las parodias de palabras y expresiones son en él más frecuentes que las de situación y que, en principio, se incluyen en cualquier contexto métrico que emplea el cómico, si bien resultan más fáciles de rastrear en contexto anapéstico o dactílico. Aristófanes se apropia con gran libertad de sus posibles modelos, repitiéndolos literalmente, deformándolos para sorprender y hacer reír a su público, inventando incluso, versos de aire homérico o épico. Hemos visto que a la hora de parodiar y modificar sus modelos Aristófanes recurre a la sustitución de unas palabras por otras o al empleo de combinaciones de palabras épicas que nunca se dan juntas o a su situación en una sede métrica inadecuada. En esas condiciones es dudoso que versos de apariencia épica pero sin paralelos evidentes en ese género y que no tienen más testigos que Aristófanes formaran alguna vez parte de poemas épicos perdidos y no sean, simplemente, una invención del cómico, un falso epicismo.Es notable también que en la mayoría de los ejemplos que hemos analizado no hemos encontrado paralelos en los autores trágicos y que con mayor frecuencia de la que a priori cabría esperar nuestro poeta es el único o casi el único autor que entre los siglos VIII y V a.C. emplea expresiones o versos homéricos y épicos, por delante de los cultivadores de otros géneros, como la lírica o la tragedia recién mencionada, tradicionalmente considerados más cercanos a Homero que la comedia. Una situación sorprendente, para la que hemos apuntado una posible explicación, pero que resulta digna de un estudio específico, que sobrepasa los límites de este trabajo. 